\title{
Description and rediagnosis of the crested hadrosaurid (Ornithopoda) dinosaur Parasaurolophus cyrtocristatus on the basis of new cranial remains
}

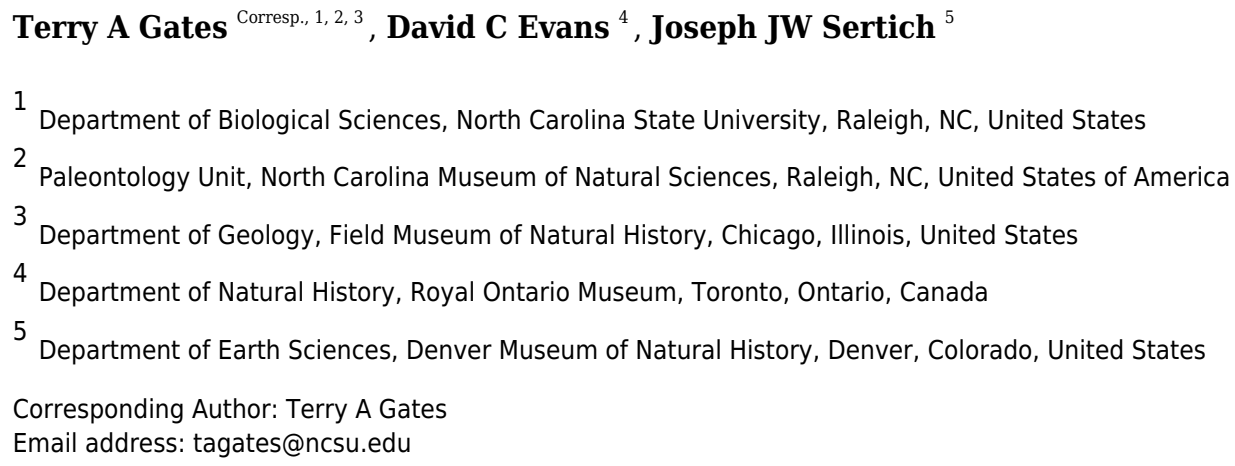

For nearly sixty years, skulls of Parasaurolophus species have been differentiated primarily on the basis of crest shape rather than on unique morphologic characters of other cranial elements. Complicating matters is the fact that crests dramatically change shape throughout ontogeny. Without a complete growth series, it has become difficult to assess the taxonomic distinctness of each species through the lens of allometric growth. Parasaurolophus cyrtocristatus has proven to be especially troublesome to assess because of the poorly preserved nature of the type and only skull. A new, partial skull from the Fossil Forest Member of the Fruitland Formation-the same geologic unit as the type specimen-is the first opportunity to re-diagnose this species as well as redefine the genus with many new traits. An undescribed, short-crested subadult skull from the Kaiparowits Formation of Utah previously assigned to cf. P. cyrtocristatus allows detailed comparisons to be made between the unnamed Utah taxon and the material of this species from the type locality. We find that several characteristics of the squamosal, supraoccipital, and premaxilla shared between the referred skull and the type skull are unique to $P$. cyrtocristatus (senso stricto) within the genus, irrespective of the overall crest shape. A phylogenetic analysis that includes six new characters posits that $P$. cyrtocristatus and $P$. tubicen are sister taxa, and that the latter does not share a closest common ancestor with the long-crested $P$. walkeri as previously hypothesized. This result helps to explain why both taxa are found in northeastern New Mexico, USA and in sequential geologic units (Fruitland Formation and Kirtland Formation, respectively). Additionally, the exquisitely preserved new skull provides the first opportunity to unequivocally identify the osteological make-up of the Parasaurolophus cranial crest. Unlike in previous 
reconstructions, the crest composition in Parasaurolophus follows what is seen in other lambeosaurines such as Corythosaurus, where the dorsal process of the premaxilla dominates the crest, with the nasal forming $80 \%$ of the ventral paired tubes, and the lateral premaxillary process acting a lateral cover between the dorsal and ventral tubes. The skull of $P$. cyrtocristatus is still incompletely known, so more complete material will likely reveal new features that further differentiate this species and aid in determining the pace of ornamental crest evolution. 


\section{Description and rediagnosis of the crested}

2 hadrosaurid (Ornithopoda) dinosaur Parasaurolophus

3 cyrtocristatus on the basis of new cranial remains

4

Terry A. Gates ${ }^{1,2,3}$, David C. Evans ${ }^{4}$, Joseph J.W. Sertich ${ }^{5}$

1 Department of Biological Sciences, North Carolina State University, Raleigh, NC, USA

2 Paleontology Unit, North Carolina Museum of Natural Sciences, Raleigh, NC, USA

3 Department of Geology, Field Museum of Natural History, Chicago, IL, USA

${ }^{4}$ Department of Natural History, Royal Ontario Museum, Toronto, ON M5S 2C6, Canada

${ }^{5}$ Department of Earth Sciences, Denver Museum of Nature \& Science, Denver, CO, USA

Corresponding Author:

Terry A. Gates

David Clark Labs, 100 Brooks Ave., North Carolina State University, Raleigh, NC 27695, USA

Email address: tagates@ncsu.edu

\section{Abstract}

For nearly sixty years, skulls of Parasaurolophus species have been differentiated primarily on the basis of crest shape rather than on unique morphologic characters of other cranial elements. Complicating matters is the fact that crests dramatically change shape throughout ontogeny. Without a complete growth series, it has become difficult to assess the taxonomic distinctness of each species through the lens of allometric growth. Parasaurolophus cyrtocristatus has proven to be especially troublesome to assess because of the poorly preserved nature of the type and only skull. A new, partial skull from the Fossil Forest Member of the Fruitland Formation-the same geologic unit as the type specimen-is the first opportunity to re-diagnose this species as well as redefine the genus with many new traits. An undescribed, shortcrested subadult skull from the Kaiparowits Formation of Utah previously assigned to cf. $P$. cyrtocristatus allows detailed comparisons to be made between the unnamed Utah taxon and the material of this species from the type locality. We find that several characteristics of the squamosal, supraoccipital, and premaxilla shared between the referred skull and the type skull are unique to $P$. cyrtocristatus (senso stricto) within the genus, irrespective of the overall crest shape. A phylogenetic analysis that includes six new characters posits that $P$. cyrtocristatus and $P$. tubicen are sister taxa, and that the latter does not share a closest common ancestor with the long-crested $P$. walkeri as previously hypothesized. This result helps to explain why both taxa are found in 
40 northeastern New Mexico, USA and in sequential geologic units (Fruitland Formation

41 and Kirtland Formation, respectively). Additionally, the exquisitely preserved new skull

42 provides the first opportunity to unequivocally identify the osteological make-up of the

43 Parasaurolophus cranial crest. Unlike in previous reconstructions, the crest composition

44 in Parasaurolophus follows what is seen in other lambeosaurines such as

45 Corythosaurus, where the dorsal process of the premaxilla dominates the crest, with the 46 nasal forming $80 \%$ of the ventral paired tubes, and the lateral premaxillary process

47 acting a lateral cover between the dorsal and ventral tubes. The skull of $P$. cyrtocristatus

48 is still incompletely known, so more complete material will likely reveal new features that

49 further differentiate this species and aid in determining the pace of ornamental crest

50 evolution.

51

52

53

54

55

56

57

58

59

60

61

62

63

64

65

66

67

68

69

70

71

72

73

74

75

76

77

78

79

\section{Introduction}

Parasaurolophus is a genus of duck-billed dinosaur that is most strikingly characterized by a tubular crest that extends over the top of the skull and beyond the occiput. Internally, the crest is hollow, housing the nasal cavity that has a shape previously described as simple U-shaped tubes with blind tubular diverticulae (Weishampel, 1997; Sullivan \& Williamson 1999). Three species of Parasaurolophus have been described and are currently recognized as valid, all found in the Campanian (Late Cretaceous) of western North America (Fig. 1). Parasaurolophus walkeri (Parks, 1922 ) is known from a single complete skull and almost complete skeleton from the Dinosaur Park Formation ( 77-76 Ma; Eberth, 2005 sensu Fowler, 2017) of Alberta, Canada, and several isolated braincases (Evans et al. 2007; Evans et al. 2009). Twothousand kilometers south, in the Kirtland Formation ( 75-73.3 Ma; Fassett \& Heizler, 2017) of New Mexico, the crest and partial skull of $P$. tubicen was discovered (Wiman, 1931). A more complete skull of this species is now known (Sullivan \& Williamson, 1999). Unlike $P$. walkeri and $P$. tubicen, which have long slightly curving crests, Parasaurolophus cyrtocristatus is unique in having a shorter crest that curves sharply ventrally over the posterior end of the skull roof. Ostrom (1961) named the species from a single (FMNH P-27393) partial, poorly preserved skull with an associated, reasonably complete and well-preserved skeleton discovered in the Fruitland Formation ( 76.1-75 Ma; Fassett \& Heizler, 2017) of New Mexico by Charles Sternberg in 1923 (Ostrom, 1961).

Though poorly preserved, the type and only previously known specimen of $P$. cyrtocristatus possesses the distinct crest morphology that easily differentiated the species from either $P$. walkeri or $P$. tubicen, yet this trait also was the sole source of evidence for suggesting sexual dimorphism within the genus (Hopson, 1975; Williamson, 2000). A consequence of the sexual dimorphism hypothesis is that if $\mathrm{FMNH}$ P-27393 was a sexual dimorph of either of the two long crested species, that would 
80 mean that the name $P$. cyrtocristatus would ergo be a junior synonym of a different species. Authors have rebuked this hypothesis based on stratigraphic and geographic separation of species (Sullivan \& Williamson, 1999; Lund \& Gates, 2006; Gates et al., 2007) leaving $P$. cyrtocristatus as a valid species.

From a taxonomic perspective, the problem with Parasaurolophus cyrtocristatus is that the specific diagnosis is based mostly on crest shape, which is known to change in all lambeosaurines through ontogeny (Dodson, 1975; Evans, Forster \& Reisz, 2005; Evans, 2010; Brink et al., 2014), but clearly differs from the other Parasaurolophus species based on the fossil material currently available. Other proposed diagnostic characteristics of this species are generally proportional differences of the postcranial skeleton (e.g., Brett-Surman, 1989). Repercussions of using the ambiguous, ontogenetically variable characteristics of crest size and shape is illustrated by the plethora of Parasaurolophus material that has arisen from the Kaiparowits Formation of southern Utah ( 77-74 Ma, Roberts et al., 2013 sensu Fowler, 2017). Beginning in 1979, partial skulls of Parasaurolophus were discovered, mostly attributed to $P$. cyrtocristatus because they all possessed a short curved crest (Weishampel \& Jenson, 1979; Sullivan \& Williamson, 1999; Lund \& Gates, 2006; Gates et al., 2007), whereas other studies have stopped short of attributing a species designation because subsequent discoveries of both juvenile specimens and more mature individuals have shown that the crest changes dramatically through growth (Farke et al., 2013; Gates et al., 2013). Overall, the Parasaurolophus material from the Kaiparowits Formation remains unnamed until a proper diagnosis of $P$. cyrtocristatus can be resolved.

A new, exquisitely preserved, partial skull of Parasaurolophus cyrtocristatus (DMNH EVP.132300) discovered in the Fossil Forest Member of the Fruitland Formation (Fig. 2) provides the first opportunity to define new species-specific diagnostic skull traits that are more robust to ontogenetic change than crest shape and present across the hypodigm. Results from this work are imperative to delineating the standing diversity of dinosaur species within the Parasaurolophus clade as well as unraveling the phylogenetic relationships among these iconic dinosaurs.

Institutional abbreviations: BYU, Brigham Young University, Provo, UT, USA; DMNH, Denver Museum of Nature \& Science, Denver, CO, USA; FMNH, Field Museum of Natural History, Chicago, IL, USA; NMMNH, New Mexico Museum of Natural History, Albuquerque, NM, USA; ROM, Royal Ontario Museum, Toronto, ON, CA; UMNH, Natural History Museum of Utah, Salt Lake City, UT, USA. \\ 115 Site Geology}

116 Hadrosaurid fossils are among the most abundant large vertebrate remains from

117 the upper Fruitland and lower Kirtland formations. As noted by Joyce, Lyson, and

118 Sertich (2018), fossils from this interval have traditionally been grouped into the 'Hunter

119 Wash Local Fauna,' the fossiliferous horizons in the upper 12.2 meters of the Fruitland 
120 Formation and the lower $16.8 \mathrm{~m}$ of the Kirtland Formation in the Hunter Wash area

121 (Clemens, 1973; Sullivan and Lucas, 2003, 2006).

122 The contact between the Fruitland and Kirtland formations was characterized

123 originally as gradational, with sandier sediment in the Fruitland Formation compared to

124 the overlying Kirtland Formation (Bauer, 1916). Later, Fassett and Hinds (1971) defined

125 the contact as the top of the highest coal or carbonaceous shale, providing the

126 foundation for more recent research (Fassett, 2000, 2010). The trouble is that the

127 gradational shift between formations makes the definition geologically problematic.

128 Other attempts to define the contact (e.g., Hunt and Lucas, 1992; Lucas et al.,

129 2006) used the base of the 'Bisti Member' or 'Bisti Bed' sandstone, as the top of the

130 Fruitland Formation or the base of the overlying Farmington Sandstone Member

131 ('Farmington Member'). Using either definition, the new P. cyrtocristatus locality (DMNH

132 loc. 7047) falls within the Fruitland Formation (Fig. 2). Ash beds bracket the locality, one

133 in the lower Fruitland Formation ('Dog Eye Pond' [DEP] ash of Fassett and Steiner,

134 1997) whereas the upper ash is found within the lower Kirtland Formation (Ash 2 of

135 Fassett and Steiner, 1997). Recent re-dating of these ashes produced dates of $76.14 \pm$

$1360.12 \mathrm{Ma}$ and $75.02 \pm 0.04 \mathrm{Ma}$, respectively (Fassett and Heizler, 2017). These dates

137 contrast to those recalculated by Roberts et al. (2013) and Fowler (2017) using updated

138 standards $(\mathrm{DEP}=75.16 \pm 0.41 \mathrm{Ma}$ and Ash $2=74.17 \pm 0.13 \mathrm{Ma} ; \mathrm{DEP}=76.029 \pm 0.41$

$139 \mathrm{Ma}$ and Ash $2=75.023 \pm 0.13 \mathrm{Ma}$, respectively).

140 The new Parasaurolophus skull was recovered from the base of a white, cross-

141 bedded sandstone within the Fossil Forest Member of the Fruitland Formation (Fig. 2),

142 likely representing deposition during avulsion of a large stream or river. Disarticulation

143 of the rostral and ventral portions of the skull, along with the chaotic distribution of other

144 postcranial remains at the site, suggests a period of sub-aerial exposure followed by

145 relatively little transport during deposition based on their close association. Nearly all

146 postcranial remains at the site were eroded prior to discovery, consisting only of

147 scattered axial and appendicular fragments.

\section{Materials and Methods}

\section{Field Methods}

Collection of DMNH EPV.132300 occurred in the Bisti-De-Na-Sin-Wilderness under Bureau of Land Management permit NM14009S.

\section{Phylogenetic Methods}

We utilized the phylogenetic matrix of Prieto-Márquez et al. (2018) to assess the relationships of Parasaurolophus cyrtocristatus and its congeners in light of the new information described here. Modifications to the original matrix included adding six new characters for a total of 286 characters and modified 36 from the original character codings (see Supplementary Material for complete record of changes and the new 
160 characters). Supplemental Material Figure 1 shows the placement of the measurements 161 used for character 286, the ratio of the posterior skull roof length to crest thickness, with 162 the resulting measurements found in the Supplemental Material.

163 All analyses were performed in the program PAUP 4.0a164 using character 164 ordering as specified in Prieto-Márquez et al. (2018)—except for the six characters 165 added in our study, which are all unordered-heuristic search with simple stepwise 166 addition, branch swapping via TBR, and holding 25 topologies per replicate. Iguanodon 167 bernissartensis was the designated outgroup with the remaining 61 taxa considered 168 ingroup. Bremer Decay Indices were calculated in PAUP using the same heuristic 169 parameters as listed above.

\section{Systematic Paleontology}

\section{Dinosauria (Owen, 1842)}

Ornithischia (Seeley, 1888)

Ornithopoda (Marsh, 1881)

Iguanodontia (Dollo, 1888) sensu (Sereno, 1986) urn:Isid:zoobank.org:act:07C25E646C15-40C3-8A61-A6378D8494AD Hadrosauridae (Cope, 1870) sensu (Prieto-Marquez, 2010) urn:Isid:zoobank.org:act:59C23C38-0AAC-4734-81A0-F38B024AFC9F Lambeosaurinae (Parks, 1923) urn:Isid:zoobank.org:act:9ACD7CF5-9014-43FF-8C7157CF9EBEC204

Parasaurolophini (Brett-Surman, 1989) urn:Isid:zoobank.org:pub:54A1A824-214D42C5-8626-D1479D3C8538

Parasaurolophus (Parks, 1922) urn:Isid:zoobank.org:act:A287F206-E5B2-48D1-B5EF86B25B48FA97

Revised diagnosis $\left(\S\right.$, characters derived from phylogenetic analysis; ${ }^{\prime}$, character found in this study) Lambeosaurine hadrosaurid taxon with the following unique traits: dorsal premaxillae extending posterodorsally over skull roof to form paired tubular chambers for narial canal (Evans, Reisz \& Dupuis, 2007); common median chamber covered by lateral premaxillary process (Evans, Reisz \& Dupuis, 2007); nasals extending posterodorsally nearly to end of crest in order to form hollow tubular chambers of narial canal (Evans, Reisz \& Dupuis, 2007); jugal with anterior process that possesses large, dorsally directed lacrimal finger and an indentation posterior that accepts corresponding finger on the lacrimal ${ }^{\hat{\delta}}$; rostral apex of rostral process of jugal reduced to a short process, only slightly thinner rostrally and ending abruptly§ (Prieto-Marquez, 2010; Prieto-Márquez et al., 2018); frontonasal platform extended posterodorsally to underlie crest (lengthens through ontogeny) (Sullivan \& Williamson, 1999; Evans, Reisz \& Dupuis, 2007); 
200 frontonasal platform thickened and steeply angled (Evans, Reisz \& Dupuis, 2007);

201 precerebral region of frontal short, anterior processes of conjoined frontals meet at a

202 widely obtuse angle in dorsal view and median cleft is poorly developed (Evans, Reisz

203 \& Dupuis, 2007); olfactory depression of frontal is offset ventrally from roof of cerebral

204 fossa (Evans, Reisz \& Dupuis, 2007).

205

206

207

Additional unique combination of traits that differentiate Parasaurolophus from other hadrosaurids include: jugal has extremely deep posterior constriction, with a ratio greater than 1.35 (mean ratio of 1.43)§ (Prieto-Marquez, 2010; Prieto-Márquez et al., 2018); dorsal margin of infratemporal fenestra as wide as, or narrower than, quadrate cotylus and squamosal ramus of postorbital relatively short over infratemporal fenestra $\$$ (Evans \& Reisz, 2007; Prieto-Márquez et al., 2018); development of deltoid ridge dorsoventrally deep and anteroposteriorly long, with a well demarcated ventral margin§ (Prieto-Marquez, 2010; Prieto-Márquez et al., 2018); overall proportions of humerus (measured as a ratio between the total length and the width of the lateral surface of the proximal end of the humerus) relatively short and stocky, ratio less than 4.25 (mean ratio of 3.85)§ (modified from Weishampel, Norman \& Grigorescu, 1993; Prieto-Márquez et al., 2018); length of ulna relative to its dorsoventral thickness (measured at mid-shaft) ratio length/width less than 10\$ (Prieto-Marquez, 2010; Prieto-Márquez et al., 2018); supraacetabular crest of ilium projects lateroventrally to overlap totally or at least half of lateral ridge of the posterior prominence of ischiadic peduncle§ (modified from Horner, Weishampel \& Forster, 2004; Prieto-Márquez et al., 2018).

221

222

\section{Remarks}

223

224

Sullivan and Williamson (1999) most recently revised the diagnosis of Parasaurolophus and Evans et al. (2007) provided additions to that diagnosis. In the above diagnosis, characters related to the crest were described individually in order to show how the elements contributed to overall shape of the crest. We removed reference to the length the crest previously mentioned in Sullivan and Williamson (1999) because that is recognized as an ontogenetic feature (Evans, Reisz \& Dupuis, 2007; Farke et al., 2013). Additionally, unambiguous synapomorphies derived from the phylogenetic analysis performed in this study were included in the diagnosis (Prieto-Márquez et al., 2018 and references therein). These synapomorphies were included in either the apomorphic or differential diagnosis if, after being traced on the phylogeny produced in this study, they were exclusively found within the Parasaurolophus clade or were shared with other lambeosaurine taxa, respectively. Prior diagnoses (Sullivan \& Williamson, 1999; Evans, Reisz \& Dupuis, 2007) included the prefrontal lapping onto the anteroventral surface of the premaxilla, but we removed that trait from this diagnosis because that is a feature of all lambeosaurine hadrosaurids. 
239 Parasaurolophus cyrtocristatus (Ostrom, 1961) urn:Isid:zoobank.org:act:842E6EA5-

240 236F-4FE6-A406-86949A68792A

241

242

243

244

245

246

247

248

249

250

251

252

253

254

255

256

257

\section{Holotype}

FMNH P-27393: Partial skull composed of nearly complete right premaxilla, posterior portion of left premaxilla, mostly complete right nasal, skull roof, partial braincase, and mostly complete postcranial skeleton

\section{Type locality, horizon, and geologic age}

As reported in Ostrom (1961, p. 575), "Fruitland [F]ormation...near Coal Creek, eight miles southeast of Tsaya, McKinley County, New Mexico." Specific locality information has been the topic of speculation by several authors (e.g., Wolberg et al., 1988; Sullivan \& Williamson, 1999; Sullivan \& Lucas, 2014). Consensus among these studies suggests an error in Sternberg's original handwritten notes, and the locality is instead eight miles northeast of Tsaya, placing it within the bounds of the Fossil Forest Research Natural Area (RNA). Numerous historic quarries in the Fossil Forest RNA have been documented and may include the type locality of $P$. cyrtocristatus (Hunt, 1991; Sullivan \& Lucas, 2014). Sullivan and Lucas (2014) further extrapolate, based on previous mapping reports (Brown, 1983; Strobell et al., 1985), that the type locality of $P$.

258 cyrtocristatus is actually located in the lower Kirtland Formation rather than the Fossil

259 Forest Member of the Fruitland Formation. However, in light of disagreement over the exact nature of the contact between the Fruitland and Kirtland as discussed above, and firsthand investigations of the Fossil Forest RNA by JJWS, we are confident that nearly all exposures within the Fossil Forest RNA are within the upper Fossil Forest Member of the Fruitland Formation. Placement within the Fossil Forest RNA (Fig. 2) is based on the work of Sullivan and Williamson (fig. 3, 1999).

\section{Referred Materials}

268

DMNH EPV.132300: Juvenile individual with a partial skull composed of posterior

269 portion of premaxillae, complete nasals, right lacrimal, complete skull roof and braincase, partial left dentary, incomplete left surangular, fragmentary ribs.

270

271

\section{Referred material locality, horizon, and geologic age}

272

DMNH Loc. 7047, Fossil Forest Member of the Fruitland Formation in the Bisti/Den-Na-

273 Zin Wilderness, San Juan County, northwestern New Mexico. The locality is located within the upper third of the Fossil Forest Member, dated to the Upper Campanian, stratigraphically lower than Ash 2 of Fassett and Steiner (1997) dated to $75.02 \pm 0.04$ Ma (Fassett and Heizler, 2017). Specific locality information is reposited at the Denver

277 Museum of Nature \& Science, available to qualified researchers upon request. 
279 Revised diagnosis $\left({ }^{*}\right.$, character found in this study)

280 Species with the following unique traits: Long common median chamber present that is

281 equal in dorsoventral breadth to the bounding narial tracts; ; lateral premaxillary process

282 has a caudoventral extension that projects to nearly the edge of the crest ${ }^{\hat{f}}$; crest curved

283 sharply posterior to skull (Ostrom, 1961); postcotyloid process of squamosal expands

284 proximoanteriorly and tapers to form a notch of $\sim 49^{\circ}$ within the quadrate cotylus ${ }^{\hat{*}}$;

285 median ramus of squamosals inset at their ventral articulation, forming a pyramidal

286 grotto underlain by the supraoccipitals ${ }^{\text {s. }}$.

287 Additionally, this species possesses a unique suite of traits that differentiates

288 from other taxa: Crest with smooth sides (Sullivan \& Williamson, 1999); crest height to

289 skull roof length ratio $\sim 1^{\hat{k}}$; absence of the external mandibular muscle scar on anterior

290 squamosal $^{\hat{*}}$; median ramus of squamosals risen to be subvertical ${ }^{\hat{*}}$.

291

292

293

294

295

296

297

298

299

300

301

302

303

304

305

306

307

308

309

310

311

312

313

314

315

316

317

318

\section{Description}

DMNH EPV.132300 consists of a partial skull excellently preserved.

Premaxilla-The premaxillae of Parasaurolophus cyrtocristatus are almost fully known between the type specimen FMNH P-27393 (Fig. 3) and the newly referred specimen DMNH EPV.132300 (Figs. 4 \& 5). Along the oral margin of the right premaxilla, FMNH P-27393 preserves the remains of conical denticles as in other hadrosaurids. A short distance from the oral margin the narial fenestra (bony naris) originates as a rounded opening that terminates in a pinched form posteriorly. The anterior margin of the narial fenestra marks the split between the dorsal and lateral processes of the premaxilla whereas the posterior terminus of the narial fenestra marks the coalescence of the two processes to form the enclosed bony narial passage.

In $P$. cyrtocristatus, FMNH P-27393, the dorsal processes propagate up the dorsal surface of the skull in a nearly straight to subtly concave line, which differs from the straight to slightly more convex growth of the premaxillae seen on P. walkeri (ROM 768) (Fig. 1). Given the less than ideal state of preservation of P-27393 we currently attribute the difference in morphology to taphonomic deformation. There appears to be no evidence of plastic deformation on the type specimen because oval-shaped sandstone steinkerns of the narial passage are observable where the now eroded left anterior premaxilla resided. These sandstone tubes are uniformly straight and have a consistent measurement of $5 \mathrm{~cm}$ in maximum width and $3.5 \mathrm{~cm}$ perpendicular to that maximum. Therefore, we regard this morphology as original and distinctive.

Uncrushed open crest sutures on the referred juvenile specimen DMNH EPV. 132300 clearly demonstrate that the dorsal and lateral premaxillary processes form the bulk of the cranial crest. The dorsal processes form individual tubes that create median and ventral septa to keep the airways isolated. Following the dorsal processes 
319 posteriorly reveals that they form the entire dorsal, posterior, and a minor ventral portion

320 of the supracranial crest (Fig. 6). Observation of a crest cross-section on FMNH P-

32127393 (Fig. 6) shows that during the dorsal progression of the dorsal processes of the

322 premaxillae, they remain in a simple tubular structure with relatively thin walls, whereas

323 on the posterior to ventral transition these processes develop a thick outer wall. A

324 change in external texture and crest form corresponds to the regions of

325 pachyossfication. More specifically, the external texture on the thinner-walled tube is

326 smooth and the thickened tube appears roughened. Additionally, the posteroventral tip

327 of the crest on DMNH EPV.132300 possesses a slightly 'pulled' shape that is distinct

328 from the smooth curvature of the dorsal crest. At their terminus, these premaxillary

329 dorsal processes reside between the nasals as in all other hadrosaurids.

330 Complementing the dorsal processes, the lateral premaxillary processes rise

331 along the crest as well, but instead of forming tubes, these elements form a strap that

332 passes on the medial side of the prefrontals above the skull roof. They continue as

333 laminar processes, covering the oblong opening created by the tubular dorsal

334 premaxillary processes and the nasals, referred to as the common median chamber. The bone texture of the lateral processes on FMNH P-27393 has a flat conchoidal shape that is not seen on DMNH EPV.132300. The latter specimen perfectly preserves the lateral processes, showing that on their terminus they possess a long tab that extends ventrally to onlap the posterior portion of the dorsal processes (Fig. 6). Additionally, as seen on DMNH EPV.132300, the lateral processes do not fully converge with the dorsal processes at the terminus of the crest, leaving a fontanelle as reported for the juvenile-aged Parasaurolophus sp. by Farke et al. (2013). FMNH P27393 does not show clearly the fontanelle, although an eroded portion in the same region as the DMNH EPV.132300 fontanelle is seen on the right side; therefore, it seems that this feature closes on Parasaurolophus cyrtocristatus through ontogeny, but a better preserved, more mature individual is needed to confirm this.

Nasals-The anterior half of the nasals can be observed on DMNH EPV.132300 underlying the premaxillary processes. They share a long straight articulation with the lacrimal along their lateral edge (Fig. 7). While supported ventrally by the frontonasal platform, the nasals also contact the prefrontals laterally (Fig. 4), sharing an extended articulation with this element and the lacrimal anterior to the platform. Though not well preserved, it appears on FMNH P-27393 that the paired nasals form the ventral portion of the distinctive tubular narial crest of parasaurolophs, and indeed DMNH EPV.132300 confirms that the nasal forms approximately $80 \%$ of lower tubes at an earlier ontogenetic stage. Upon emerging from the fronto-nasal platform, these paired elements form complete tubes and propagate posteriorly along the base of the crest until they articulate with the dorsal premaxillary process a short distance from the posterior crest terminus (Figs. 4, 5, and 6). As in all other hadrosaurids, the nasals form 
359 a V-shaped opening into which the dorsal premaxillary processes insert. A cross-section

360 of the crest on FMNH P-27393 shows that the nasal tubes were divided from each

361 counterpart by a median septum. Just anterior to the frontonasal platform the nasal

362 tubes converge into a single rounded chute.

363

364 Lacrimal—A mostly complete lacrimal is present on DMNH EPV.132300, but lacking in

365 the $P$. cyrtocristatus type specimen. It has the same general morphology of other

366 hadrosaurid lacrimals in being triangular in lateral view, but also possesses the

367 synapomorphic large notch on the ventral surface that accepts the corresponding

368 process from the jugal as seen on $P$. walkeri (ROM 768) and $P$. tubicen (NMMNH P-

369 25100). Medially, the lacrimal shares a long articular surface with the nasal (Fig. 7). It

370 articulates with the prefrontal posterodorsally through a ' $V$ '-shaped notch in the lacrimal

371 that accepts a long corresponding process of the latter element. Ventral to the prefrontal

372 articulation on the posterior side of the lacrimal is the opening for the lacrimal foramen.

373 Unlike the widening posterior lacrimal face seen in some saurolophines (e.g.,

374 Gryposaurus (Gates \& Sampson, 2007), Acristavus (Gates et al., 2011)), that of DMNH

375 EPV.132300 maintains a single width throughout its posterior height. A difference in

376 lacrimal morphology can be seen in P. walkeri such that this element of ROM 768

377 protrudes posteriorly into the orbit, whereas that of DMNH EPV.132300 is smoothly

378 arching. Given that only a single specimen is known of $P$. walkeri, individual variation

379 could explain the difference in lacrimal morphology seen in this species versus $P$.

380 cyrtocristatus, but until more specimens are acquired, we consider this to be a species-

381 specific trait. That of $P$. tubicen (NMMNH P-25100) seems to correspond in shape to

382 DMNH EPV.132300.

383

384

385

386

387

388

389

390

391

392

393

394

395

396

397

Prefrontal-Among lambeosaurines, the prefrontal forms the base of the crest complex, forming a supporting structure on the ventrolateral section of the crest (Lull \& Wright, 1942). Parasaurolophus cyrtocristatus (DMNH EPV.132300 and FMNH P-27393), and other Parasaurolophus species more generally, follow this pattern, but also exaggerate the size of the prefrontal compared to lambeosaurins (Evans \& Reisz, 2007; Evans, 2010). In DMNH EPV.132300, the prefrontal is tightly sutured to the postorbital laterally. There is a small foramen with a posteriorly directed furrow just dorsal to the postorbital suture near the orbital rim. As one follows the orbital margin from the postorbital anteriorly on the prefrontal, the rugose texture becomes less pronounced in conjunction with a decreasing prominence of the brow.

Articulation with the lacrimal occurs along the 'V'-shaped process on the anterior margin. Medial to this articulation, the prefrontal flattens to contact the ventrolateral side of the nasals as they project along the base of the crest complex. This arrangement continues posterodorsally as the crest rises beyond the skull roof. The prefrontal in all 
398

399

400

401

402

403

404

405

406

407

408

409

410

411

412

413

414

415

416

417

418

419

420

421

422

423

424

425

426

427

428

429

430

431

432

433

434

435

436

437

species of Parasaurolophus extends posterodorsally farther than in other lambeosaurines.

Frontal-Only the posterior half of the frontals are visible on DMNH EPV.132300 and FMNH P-27393 because of articulation with the crest-forming elements and sediment matrix in-filling. Though it is not seen on any $P$. cyrtocristatus specimen, the frontonasal platform likely conforms to that of both $P$. walkeri and $P$. tubicen in consisting of a highly angled striated platform (Wiman, 1931; Evans, Reisz \& Dupuis, 2007; Evans, Bavington \& Campione, 2009). The anterior damage to the frontal of FMNH P-27393 mentioned by Sullivan and Williamson (1999) is erosion of the dorsal premaxillary process ventral tube margin. Evans et al. (2007) noted that the body of Parasaurolophus frontals is extremely anteroposteriorly shortened, declaring this trait a synapomorphy of the genus. The frontal body of the type specimen and DMNH EPV.132300 differ only in that the latter specimen is highly domed, a trait seen in other juvenile lambeosaurs (Evans, Forster \& Reisz, 2005). Posteriorly, the frontonasal platform is observed as paired, flat struts that ventrally support the nasals of the crest spanning either a short distance along the base of the crest as in DMNH EPV.132300 (relative length of 0.07) or nearly half the length of the ventral crest in FMNH P-27393 (relative length of 0.19 , see Supplementary Material for measurements), likely as a consequence of growth stage. One of the most obvious similarities between members of Parasaurolophus and the clade's sister taxon Charonosaurus is the striated, highly angled, and posterodorsally expanding frontal platform (Godefroit, Zan \& Jin, 2001). Although it does appear, based on Godefroit et al. (2001) figure 4A, that the frontal platform is mediolaterally broader than that in Parasaurolophus. More detailed comparisons are needed of this element between the two taxa.

Postorbital-The tripartite postorbital has an anteromedial arm that robustly contacts the prefrontal, frontal, and minorly on the parietal. A second ventrally directed arm articulates with the jugal, and the third, posteriorly oriented arm, overlaps the anterior process of the squamosal. Along the postorbital contribution to the orbit the DMNH EPV.132300 postorbital is bubble-shaped, being much more rounded dorsally than the anterior portion of the orbit composed of the prefrontals. This region of the orbital rim also possesses minor rugose texturing. A foramen $5 \mathrm{~mm}$ wide resides near the orbital rim. Overlap of the postorbital onto the squamosal is accomplished through a wide scarf joint that is weakly bipartite as in the Corythosaurus specimen AMNH 5386 and Hypacrosaurus altispinus (Evans, 2010). Other hadrosaurs have two equally long processes including lambeosaurs (e.g., Velafrons; (Gates et al., 2007) or saurolophines generally (Prieto-Marquez, 2010; Gates et al., 2011)), but the articular facets can also be jagged as in $H$. stebingeri (MOR 553S 7-27-2-93). 
438 Parietal-Following the form of other lambeosaurines, this element is slightly hourglass 439 shaped articulating with the frontal anteriorly along a long suture. There are unobserved 440 sutures to other elements, presumably the prootic and exoccipital, that have been 441 overgrown with bone. Posteriorly, the parietal of Parasaurolophus cyrtocristatus takes 442 on a more distinct form by increasing its height to be higher than any other lambeosaur 443 except $P$. tubicen. The sagittal crest begins at the midpoint of the parietal, following posteriorly to bisect the squamosals (Fig. 8).

Squamosals-Being one of the more distinctive elements in the DMNH EPV.132300 cranium, the squamosals are best described in congruence with multiple elements. They articulate with the postorbitals anteriorly via scarf joint; medially, the parietal separates the paired squamosals with a narrow wedge that becomes extremely thin posteriorly and ventrally, a feature shared among lambeosaurs (Prieto-Marquez, 2010); and ventrally the squamosals are underlain by the supraoccipital. Of minor consequence to the gross morphology is the scarf joint between the postcotyloid process and paroccipital process of the exoccipital-opisthotic.

As in many other lambeosaurines, the dorsal aspect of the squamosal median processes are broadened into a partial canopy over the dorsal temporal fenestrae. However, unlike species such as Hypacrosaurus stebingeri (MOR 553S 7-27-2-93), $\mathrm{H}$. alitspinus (Evans, 2010), Corythosaurus casuarius (AMNH 5386), and Olorotitan arharensis (Godefroit, Bolotsky \& Bolotsky, 2012) in which the broadened median processes obscure a larger portion of the dorsal temporal fenestra, within Parasaurolophus cyrtocristatus (both DMNH EPV.132300 and FMNH P-27393) the squamosals adhere to parietals that are elevated well above the level of the anterior parietals. As such, each median process creates more of a posterior wall than shading the dorsal temporal fenestra (Fig. 8). Godefroit et al. (2004) describe the median region of the Aralosaurus squamosal rising well-above the paroccipital process, but the condition observed, at least in their figure 5 , is still well below the height observed in $P$. cyrtocristatus. Charonosaurus (Godefroit, Zan \& Jin, 2001) does not preserve this region of the squamosals. Interestingly, $P$. tubicen shares the trait of the greatly elevated squamosals and parietals with $P$. cyrtocristatus (PMU.R1250 and NMMNH P25100 ), but the trait is not present in $P$. walkeri (ROM 768). Additionally, when viewed posteriorly, it becomes apparent that the dorsal tip to the median process along with the sandwiched parietal extend project posteriorly further than the proximal main squamosal body, forming an anteroventrally-oriented angle that terminates at the supraoccipital. Since the latter element is flat, the resulting morphology is a distinct pyramidal grotto that is unique to $P$. cyrtocristatus (Fig. 8).

476 (Fig. 8). First, the postcotyloid process is expanded dramatically at its proximal region, so much so, that the quadrate cotylus is nearly walled along its medial border. This 
478 feature is seen both on DMNH EPV.132300 and FMNH P-27393 to nearly the same 479 angulation (42 and 49 degrees, respectively, at their widest point). Expansion of the 480 postcotyloid process tapers ventrally in a straight line. $P$. tubicen also shares an 481 expanded, but tapering, postcotyloid process, although the condition in this species is 482 less dramatic that in $P$. cyrtocristatus. The same region is obscured in $P$. walkeri (ROM 483 768). Outside of lambeosaurines, an analogous expansion can be found in several 484 saurolophs, notably Prosaurolophus, Kundurosaurus (Godefroit, Bolotsky, and Lauters,

485

486

487

488

489

490

491

492

493

494

495

496

497

498

499

500

501

502

503

504

505

506

507

508

509

510

511

512

513

514

515

516

517

2012), and Naashoibitosaurus. In each of these taxa, the postcotyloid process expansion forms a squared-off tab instead of a proximal expansion as described above. Edmontosaurus annectens shares a subdued version of the postcotyloid tab. This trait seems to be a synapomorphy of those hadrosaurids most closely related to Prosaurolophus. A second interesting trait of the Parasaurolophus cyrtocristatus squamosal is that the deep triangular scar for external mandibular musculature seen in other hadrosaurids (Gates \& Sampson, 2007) is absent in all species of Parasaurolophus.

Braincase-The braincase of DMNH EPV.132300, is well preserved, although the sutures between individual elements are difficult to discern (Figs. 4, 5, and 9), making an accurate deconstruction of this element complex impossible without the assistance of internal inter-element observations aided by commuted tomography. However, Figure 9 shows the various structures present on the braincase of DMNH EPV.132300 that are identifiable irrespective of element sutures.

Basisphenoid-Parasphenoid complex-From the incomplete parasphenoid (Figs. 4, 5, and 9), the rounded anterior process becomes slightly concave when followed posteriorly. Simultaneously with the changes in the presphenoid process, two sharply defined ridges form laterally, which widen during their posterior progression. As they descend the basipterygoid (Figs. 4, 5, and 9) processes the sharp ridge dissolves again into rounded pendant-shaped bones. Between the two basipterygoid is a lamina that delineates the divide between a triangular concave region anteriorly and a shear wall posteriorly. Absent from this lamina is a small ventral projection that can be seen on other taxa including Hypacrosaurus altispinus (Evans, 2010), Hypacrosaurus stebingeri (MOR 553S 7-27-2-93), Corythosaurus (Evans, 2010), and Amurosaurus (Godefroit, Bolotsky \& Itterbeeck, 2004). At the base of the wall is a deep groove that runs posteriorly from this point (approximately mid-length of the basisphenoid) to the posterior terminus of the bone, with the groove extending slightly onto the basioccipital. Other taxa that possess the same deep fossa are H. stebingeri (MOR 553S 7-27-2-93) and Charonosaurus (Godefroit, Zan \& Jin, 2001).

Alar processes are minutely developed on this taxon, being only tiny teardropshaped projections just anterior to the Vidian Canal. This trait is shared with

Peer) reviewing PDF | (2020:01:44845:2:1:NEW 3 Dec 2020) 
518 Parasaurolophus tubicen (NMMNH P-25100), whereas other hadrosaurs have more

519 developed alar processes (e.g., Charonosaurus (Godefroit, Zan \& Jin, 2001),

520 Hypacrosaurus altispinus (Evans, 2010), Olorotitan (Godefroit, Bolotsky \& Bolotsky,

521 2012), and Amurosaurus (Godefroit, Bolotsky \& Itterbeeck, 2004)).

$522 \quad$ Fusion of the basisphenoid with the basioccipital is clearly discernible, being

523 demarcated by the basisphenoid cupping the anterior tubercles of the basioccipital. A

524 combination of the central groove and broad articulation of these two elements gives the

525 basisphenoid cups a 'mouse-ear' appearance.

526

527

Basioccipital-The anterior morphology of the basioccipital (Figs. 4, 5, 8, and 9) is

528 predicated by the deep fossa that depresses the posterior basisphenoid and projects

529 this depression onto the basioccipital. As such, the laterally positioned basitubera are

530

531 elevated relative to the median depression as well as to the basioccipital body just posterior to the basitubera. The posterior margin of the basioccipital that contributes to the occipital condyle is only slightly enlarged compared to the central portion of the element. In posterior view, this articular facet has an ovoid heart shape, and comprises the central-most floor of the foramen magnum. Overall, the gross morphology of the basioccipital does not differ from that seen in other lambeosaurine hadrosaurs.

Exoccipital-opisthotic complex-Situated posterodorsally to the basioccipital, the exoccipital (Figs. 4, 5, 8, and 9) composes the remainder of the pendant-shaped foramen magnum. Two blunt processes rest on the posterodorsal surface of the basioccipital and project posteriorly approximately $1 \mathrm{~cm}$ beyond the latter element. The fused opisthotic can be seen descending lateroventrally from the laterodorsal surface of the exoccipital. A separation between the opisthotic and the paroccipital process of the squamosal shows that the opisthotic descended slightly beyond the ventral tip of the squamosal. This elongated condition differs dramatically from the rounded spatula shape of the opisthotics in Charonosaurus (Godefroit, Zan \& Jin, 2001). Hypacrosaurus stebingeri (MOR 553S 7-27-2-93) possesses opisthotics that rise well above the level of the squamosals. This condition is not possible in Parasaurolophus cyrtocristatus because of the vaulted squamosals.

Just dorsal to the foramen magnum, the DMNH EPV.132300 exoccipital forms an anteroventrally inclined shelf that meets the supraoccipital along its dorsal margin, similar to the depressed exoccipital of Olorotitan (Godefroit, Bolotsky \& Bolotsky, 2012). Hypacrosaurus stebingeri (MOR 553S 7-27-2-93), H. altispinus (Evans, 2010), Velafrons (Gates et al., 2007), and Amurosaurus (Godefroit, Bolotsky \& Itterbeeck, 2004) do not possess the same morphology, but instead have a shorter margin between the foramen magnum and the supraoccipital, which decreases the length and angle of descent on this portion of the exoccipital. 
558 Supraoccipital-Exposure of the supraoccipital (Figs. 5 and 8) is limited to a small 559 triangular shelf dorsal to the exoccipitals and ventral to the squamosals. In DMNH

560 EPV.132300, the combination of the squamosals and the supraoccipital form a tall

561 pyramidal grotto that differs from the condition seen in Parasaurolophus tubicen

562 (PMU.R1250, Sullivan \& Williamson, 1999, fig. 8) and other lambeosaurines.

563

564

565

Orbitosphenoid-This small cuniform bone articulates with the frontal medially and dorsally, and with the laterosphenoid posteriorly and ventrally (Figs. 4 and 9). It houses the opening for cranial nerve II, but is otherwise a simple, laminar element.

Laterosphenoid-Occupying a central position on the braincase, the left laterosphenoid of DMNH EPV.132300 is preserved in its entirety (Figs. 4 and 9). Dorsally, the laterosphenoid meets the parietal along a linear, anteroposteriorly directed suture. The capitate process of the laterosphenoid articulates dorsolaterally with the postorbital medial to the midpoint of the central lamina of the postorbital. Anteriorly, the laterosphenoid meets the lamina of the orbitosphenoid in a simple, linear suture, continuing anterodorsally to form a simple suture with the frontal. Posteriorly, the laterosphenoid meets the prootic in a difficult to discern suture near the exit of CN VII. Posteroventrally, the laterosphenoid contributes to the anterior and dorsal walls of the trigeminal foramen ( $\mathrm{CN} \mathrm{V}$ ) a large, ovoid opening set within a deep recess. A deeply set groove extends anteriorly across the lateral surface of the laterosphenoid for passage of the opthalmic branch of $\mathrm{CN} \mathrm{V}$, partially roofed by a sharp crest on the laterosphenoid. A shallower groove extends anteroventrally from the trigeminal recess for passage of the maxillary and mandibular branches of $\mathrm{CN} \mathrm{V}$, partially bordered by the ventral process of the laterosphenoid.

Prootic-The prootic (Figs. 4, 5, and 9) contributes to the posterodorsal portion of the lateral braincase wall, extending ventrally from its dorsal contact with the parietal to form a laterally convex lamina. The prootic forms the posterior margin of the trigeminal foramen and the anterior and dorsal margins of the fenestra vestibuli. Between each of these openings, the prootic is pierced by the fenestra for CN VII immediately posterior to an anteroventrally-directed crest near the suture with the laterosphenoid. The prootic meets the exoccipital posteriorly.

Dentary-Only the proximal half of the right dentary (Fig. 10A and B) is preserved with DMNH EPV.132300. Overall, this partial element is typical of hadrosaurid iguanodontians. Narrow alveolar sulci extend from the approximate midportion of the element posterior to end within the rostrocaudal length of the basal coronoid process. Throughout the preserved length of the dentary, the articular facet for the angular is prominent medially, yet hidden in lateral view. The coronoid process rises nearly 
598

599

600

601

602

603

604

605

606

607

608

609

610

611

612

613

614

615

616

617

618

619

620

621

622

623

624

625

626

627

628

629

630

631

632

633

634

635

636

637

638

vertically from the dentary body with a dorsal margin that expands both rostrally and caudally, unlike the same region on Brachylophosaurus that only expands rostrally (Prieto-Márquez, 2005; Gates et al., 2011). The taxon Charonosaurus also has limited caudal expansion of the dorsal coronoid process, and additionally differs from $P$. cyrtocristatus in having a rostroventrally oriented dorsal-most surface of this process (Godefroit, Zan \& Jin, 2001). A straight ventral margin is featured on the preserved portion of the dentary.

Surangular-This element was found eroded on the surface, as such, the more delicate processes are not preserved. As shown in Figure 10C and 10D, the main surangular body is typical of iguanodontians, yet the more derived features of hadrosaurids are missing.

\section{Results}

\section{Phylogenetic Analysis}

A strict consensus tree constructed from the 72 most parsimonious topologies obtained in our phylogenetic analysis posited Parasaurolophus cyrtocristatus as sister taxon to Parasaurolophus tubicen (Fig. 11), supported by two unambiguous synapomorphies (281. Squamosals risen to be subvertical; and 283. Triangular external mandibular muscle scar anterior to precotyloid process absent). The unambiguous synapomorphies uniting all species of Parasaurolophus exclusive of other hadrosaurids are characters 103 (Rostral apex of the rostral process of the jugal reduced to a short process, only slightly thinner rostrally and ending abruptly), 111 (Relative depth of the jugal caudal and rostral constrictions (in adults) (rostral constriction region located between the rostral and postorbital processes; caudal constriction region located between the postorbital process and the caudoventral flange extremely deep with a ratio greater than 1.35), 128 (Narrowing of the dorsal region of the infratemporal fenestra being as wide as or narrower than quadrate cotylus), 216 (Development of the scapula deltoid ridge dorsoventrally deep and craniocaudally long, with a well demarcated ventral margin), 220 (Overall proportions of the humerus (measured as a ratio between the total length and the width of the lateral surface of the proximal end of the humerus) relatively short and stocky humerus, ratio less than 4.25), 221 (Length of the ulna relative to its dorsoventral thickness (measured at mid-shaft) ratio length/width less than 10), and 234 (Development of the lateroventral projection of the supraacetabular crest of the ilium projects lateroventrally to overlap totally or at least half of the lateral ridge of the caudal prominence of the ischiadic peduncle). Other clades of lambeosaurine hadrosaurids remain in the same construction as in Prieto-Márquez et al. (2018). Bremer decay indices show that the characters and codings in this analysis support a robust framework for more basal iguanodontians, whereas the clades of hadrosaurids suffer from less robust support. The Brachylophosaurini clade (Gates et al., 2011) and the clade containing the genera Augustynolophus and Saurolophus (members of the Saurolophini clade (Prieto- 
639 Márquez et al., 2014)) both have Bremer decay values greater than 4. Subclades

640 throughout the Parasaurolophini (Brett-Surman, 1989) are supported as other

641 lambeosaurine clades with Bremer values of 2 throughout.

642

643 Discussion

644 Phylogenetic and biogeographic considerations

645

646

Parasaurolophus cyrtocristatus was erected as a short-crested species of

647 Parasaurolophus by Ostrom (1961), but subsequently suggested to be a sexual dimorph of $P$. tubicen by Hopson (1975). Most recent systematic revisions of the genus Parasaurolophus have discussed the validity of Parasaurolophus cyrtocristatus and at least tentatively considered the taxon valid (Horner, 1990; Sullivan and Williamson 1999; Horner et al. 2004; Evans 2007, 2010; Prieto-Marquez 2010). Confusingly, Williamson (2000) argued that it is most parsimonious to regard $P$. cyrtocristatus as a subjective junior synonym of $P$. tubicen, yet at the same time referred BYU 2467 and UCMP 143270 to $P$. cyrtocristatus later in the same paragraph. In this study, new material affirms the validity of $P$. cyrtocristatus. The results of the phylogenetic analysis conducted in this study is the first to suggest that $P$. tubicen and $P$. cyrtocristatus are more closely related to each other than either is to $P$. walkeri. Previously, the two 'longcrested' species were hypothesized as a clade (e.g., Evans \& Reisz, 2007; Evans, 2010; Godefroit, Bolotsky \& Bolotsky, 2012; Prieto-Márquez et al., 2018) or as members of a monophyletic clade with 'Charonosaurus' jiayinensis (e.g., Xing et al., 2014b,a) in which $P$. cyrtocristatus is the sister taxon to these other parasaurolophs. Interestingly, the results of this phylogenetic analysis are more consistent with the paleobiogeographic and stratigraphic occurrences of Parasaurolophus cyrtocristatus and P. tubicen, which are both found in northern New Mexico-2000 kilometers south of the Alberta occurrences of $P$. walkeri-and in considerably younger geologic formations separated by a maximum 2.5 million years (Gates, Prieto-Márquez \& Zanno, 2012). Parasaurolophus walkeri is known only from the basal portion of the Dinosaur Park Formation (Ryan \& Evans, 2005; Evans et al., 2009), which means that there is a temporal separation of approximately 2 million years between this taxon and $P$.

670 cyrtocristatus, whereas there is a maximum 4.5 million years between the former taxon and $P$. tubicen.

Another proposed parasauroloph from North America is Adelolophus hutchisoni, a species identified from an isolated maxilla that was discovered approximately $200 \mathrm{~m}$ from the base of the Wahweap Formation, making it the oldest lambeosaurine currently known from North America (Gates et al., 2013, 2014; Holroyd \& Hutchison, 2016). Given its fragmentary nature, phylogenetic or biogeographic comparisons between this species and the other parasaurolophs are extremely limited, and we therefore refrain from making further inferences about the relationships of Adelolophus. 
679

680

681

682

683

684

685

686

687

688

689

690

691

692

693

694

695

696

697

698

699

700

701

702

703

704

705

706

707

708

709

710

711

712

713

714

715

716

717

718

\section{Comparison to the Kaiparowits Formation Taxon}

The first specimens of Parasaurolophus described from the Kaiparowits Formation possess a drastically arched crest as seen in $P$. cyrtocristatus. Despite the authors of the original description of BYU 2467 expressly opting out of providing a species referral, largely because BYU 2467 is only a poorly preserved partial crest (Weishampel \& Jenson, 1979). A second specimen, UCMP 143270 (Figs. 12 \& 13), constitutes a well preserved and complete crest with articulated upper cranium. Sullivan and Williamson (1999) and Williamson (2000) referred both BYU 2467 and UCMP 143270 to $P$. cyrtocristatus, based in on crest curvature. New preparation and study of UCMP 143270 together with the discovery of DMNH EPV.132300 gives the opportunity to test the identification of the Kaiparowits taxon with the newly described characteristics of $P$. cyrtocristatus since more recent studies have shown that crest curvature is allometric.

UCMP 143270, illustrated here for the first time, possesses the raised squamosals of $P$. tubicen and $P$. cyrtocristatus (Fig. 12). In caudal view one can see the pyramidal grotto between the squamosals and the supraoccipital (Fig. 13). The postcotyloid process seems to show a slight expansion into the quadrate cotylus, but both the right and left sides are broken so it is unclear if the expansion is as narrow as $P$. cyrtocristatus or if it is wider as in P. tubicen. The sutures of the crest are clearly visible allowing its construction to be understood in similar detail to DMNH EPV.132300. The size of the lateral premaxillary process is most comparable to that of $P$. cyrtocristatus (Fig. 12), which is certainly different than the narrower crest of $P$. walkeri or the broader crest of $P$. tubicen (Fig. 1). Finally, the lateral premaxillary process does not show a posteroventrally directed flange as in DMNH EPV.132300 (Fig. 12). This could be the result of simple breakage or individual variation, or could be an indication that this specimen is not referrable to $P$. cyrtocristatus.

After compiling evidence, and considering the possible confounding effects of individual and ontogenetic variation, we concur with Williamson (2000) and tentatively identify the Kaiparowits taxon (as exemplified by BYU 2467 and UCMP 143270) as $P$. cyrtocristatus based on the general osteological make-up of the crest, and the presence of the pyramidal grotto. If this identification holds after further detailed investigation of the increasing sample of mature individuals from the same beds, UCMP 143270 will provide an important poorly known ontogimorph of this genus and outstanding complement to DMNH EPV. 132300 for comparisons of braincase anatomy. Additionally, this taxonomic identification would add to a growing body of evidence that the Kaiparowits Formation has a close biotic relationship with both the Fruitland and Kirtland formations of northern New Mexico (e.g., ankylosaurids (Sullivan, 1999; Arbour et al., 2014; Wiersma and Irmis, 2018) and ceratopsids (Sampson and Loewen, 2010; Fowler and Freedman Fowler, 2020). 
719

720

721

722

723

724

725

726

727

728

729

730

731

732

733

734

735

736

737

738

739

740

741

742

743

744

745

746

747

748

749

750

751

752

753

754

755

756

757

758

\section{Crest composition and taphonomy}

Another important implication of this study is that DMNH EPV.132300 and UCMP 143270 are the first specimens to unequivocally show the detailed anatomy of the external crest surfaces, which has been uncertain and problematic for phylogenetic studies of this taxon. Previous studies of crest anatomy have been based primarily on the poorly preserved and/or badly crushed and difficult to interpret type specimens of the three Parasaurolophus species. Most of these studies posit an extremely small lateral premaxillary process and a small laterally exposed nasal of uncertain boundaries that does not contribute significantly to the ventral margin of the crest (Weishampel 1981b) or that forms a very small contribution to the base of the crest (Russell 1946; Sullivan and Williamson 1999). Evans et al. (2009) reviewed the various hypotheses and interpretations of crest composition in Parasaurolophus walkeri, noting that the composition of the crest in any specimen is uncertain due to ambiguities of preservation.

These two new, remarkably preserved specimens permit a detailed understanding of external crest anatomy in a species of Parasaurolophus for the first time and confirm that the paired nasals form the basal tubes along four-fifths the ventral length of the supracranial crest, and that the dorsal premaxillary process forms the narial tubes throughout the entire dorsal, posterior, and slight ventral portions of the crest. Based on this new interpretation, the composition of the crest is in fact more consistent with patterns of crest construction seen in other lambeosaurines (e.g., Corythosaurus and Lambeosaurus) in which the dorsal premaxillary process forms the crest dorsally, the lateral premaxillary process forms a large lateral portion of the crest ventral to the dorsal process, and the nasal has a significant contribution to the posterior region and base. Interestingly, this new knowledge of crest anatomy in Parasaurolophus cyrtocristatus, which we hypothesize is the general construction present in $P$. walkeri and $P$. tubicen, closely resembles a hypothesis of crest construction presented by Wilfarth (1939), where he took an evolutionary approach to interpreting origin of crest structure in Parasaurolophus tubicen.

An interesting trend in the preservation of most Parasaurolophus cranial material is the prevalence of articulated skull roofs. Specimens that consist solely or largely of this portion of cranial material include the type and referred specimens of $P$. tubicen, the type and referred specimens of $P$. cyrtocristatus, as well as the published specimens from the Kaiparowits Formation BYU 2467 and UCMP 143270. This represents over $85 \%$ of crest-yielding material of Parasaurolophus are articulated skull roofs. Even in specimens described by Evans et al. (2007) and Evans et al. (2009), the highly eroded braincases are articulated, including a juvenile specimen. Growth of the large cranial crest may require that the skull become reinforced from an early ontogenetic stage, which in part may explain the prevalence of these skull sections being preserved with such frequency. The greatly enlarged crests would certainly have put relatively more 
759

760

761

762

763

764

765

766

767

768

769

770

771

772

773

774

775

776

777

778

779

780

781

782

783

784

785

786

787

788

789

790

791

792

793

794

795

796

797

798

stress on the joints of the skull roof and braincase in Parasaurolophus relative to other hadrosaurid taxa. Increased interdigitation in the skull roof is observed in other amniote taxa as a response to increased stress (e.g., Herring 2008; Herring 1974), and this could explain the propensity for the tops of skulls to maintain cohesion and be preferentially preserved together in Parasaurolophus.

\section{Conclusions}

Ornamental cranial crests are some of the most distinguishing features of hadrosaurid dinosaurs. Consequently, the morphological distinctions between crests of various species have been thoroughly studied, often times to the detriment of identifying additional characteristics across the range of skull elements that can be used to diagnose species. Species of the genus Parasaurolophus have suffered this bias, and none as markedly as $P$. cyrtocristatus. There is little doubt that the source of this tendency stems from the poor preservation of the type and only specimen as well as from the distinct, sharply curving crest which departs from the longer, straighter crest of its congeners $P$. walkeri and $P$. tubicen.

DMNH EPV.132300 is a well-preserved new specimen of $P$. cyrtocristatus that was discovered in the Fossil Forest Member of the Fruitland Formation, the same set of rocks from which the type specimen was presumably excavated, which allows for a reassessment of the species-specific traits that make the taxon novel. Aside from the sharply curving crest (which will remain as part of the diagnosis until other, more mature specimens are recovered), we have identified a narrow notch in the quadrate cotylus of the squamosal that is formed by an expansion of the anterodorsal and posterodorsal cotylus corners, a pyramidal-shaped grotto between the squamosals and the supraoccipitals, and the lateral process of the premaxilla with a small posteroventral projecting finger along the side of the crest.

An additional six features that we identify, such as vertically projecting squamosals and an absent mandibular muscle scar on the anterolateral squamosal, are used in a new phylogenetic analysis that posits a close relationship between $P$. tubicen and $P$. cyrtocristatus. This is the first phylogenetic analysis to our knowledge that suggests this sister-taxon relationship. In our analysis, $P$. walkeri forms the basal member of the Parasaurolophus clade, which is consistent with its lower stratigraphic position.

Proper diagnosis of each Parasaurolophus species is required to fully understand the paleobiological implications of sexual selection, crest allometry, and natural selection on the overall changes observed in skull architecture. This clade of hadrosaurs is one of the iconic dinosaurs, yet so much of their evolution and paleobiology is unknown, only to be revealed by more detailed anatomical studies and the discovery of new specimens. 
799 Acknowledgements

800 DMNH EPV.132300 was discovered by Erin Spear and collected with the guidance and

801 support of Phil Gensler (BLM Regional Paleontologist) and the Farmington BLM Field

802 Office. Special thanks to the amazing DMNS volunteer field crew, especially C. Hank

803 Woolley, Larkin McCormack, Doug Shore, Andrew Spear, and Erin Spear for their

804 assistance in collecting the specimen. Preparation was expertly accomplished by Becky

805 Garfield under the supervision of Mike Getty, Natie Toth, and Salvador Bastien. We

806 thank Peter Makovicky and Bill Simpson for access to Field Museum collections. We

807 thank P. Holroyd and Mark Goodwin for the loan of the UCMP specimen to DCE for 808 preparation and study, and lan Morrison (ROM) for preparation of the specimen.

809 Andrew McDonald, Albert Prieto-Márquez, and Pascal Godefroit provided valuable

810 comments that greatly improved the manuscript. Finally, we would like to respectfully

811 acknowledge that the fossils from the San Juan Basin were collected on the traditional

812 lands of the Diné and Puebloan people, and fossils from the Kaiparowits Basin were

813 collected on the traditional lands of the Southern Paiute and Puebloan people.

814

815 References

816 Arbour VM, Burns ME, Sullivan RM, Lucas SG, Cantrell AK, Fry J, Suazo TL. 2014. A new

817 ankylosaurid dinosaur from the Upper Cretaceous (Kirtlandian) of New Mexico with

818 implications for ankylosaurid diversity in the Upper Cretaceous of western North

$819 \quad$ America. PloS one 9:p.e108804.

820 Bauer, C.M. 1916. Stratigraphy of a part of the Chaco River valley: U.S. Geological Survey

$821 \quad$ Professional Paper, 98-P, p. 271-278.

822 Brett-Surman MK. 1989. A revision of the Hadrosauridae (Reptilia: Ornithischia) and their

823 evolution during the Campanian and Maastrichtian. PhD Dissertation Thesis. George

$824 \quad$ Washingtion University.

825 Brink KS, Zelenitsky DK, Evans DC, Horner JR, Therrien F. 2014. Cranial morphology and

826 variation in Hypacrosaurus stebingeri (Ornithischia: Hadrosauridae). Hadrosaurs. Edited

827 by DA Eberth and DC Evans. Indiana University Press, Bloomington, IN:245-265.

828 Brown J. 1983. Geologic and isopach maps of the Bisti, De-na-zin and Ah-she-sle-pah

829

Wilderness Study Areas, New Mexico. 1:50,000. U.S. Geological Survey Miscellaneous

830 Field Studies Map MF-1508-A. U.S. Geological Survey, Reston, Virginia. 
831 Clemens WA. 1973. The roles of fossil vertebrates in interpretation of Late Cretaceous

832 stratigraphy of the San Juan Basin, New Mexico, in Fassett, J.E., ed., Cretaceous and

833 Tertiary Strata of the San Juan Basin: Four Corners Geological Society Memoir, p. 154-

$834 \quad 167$.

835 Cope ED. 1870. Synopsis of the extinct Batrachia, Reptilia, and Aves of North America.

836 Transactions of the American Philosophical Society 14:1-252.

837 Dodson P. 1975. Taxonomic implications of relative growth in lambeosaurine hadrosaurs.

$838 \quad$ Systematic Biology 24:37-54.

839 Dollo L. 1888. Iguanodontidae et Camptonotidae. Comptes rendus de l'Académie des Sciences $840 \quad 106: 775-777$.

841 Evans DC. 2010. Cranial anatomy and systematics of Hypacrosaurus altispinus, and a

842 comparative analysis of skull growth in lambeosaurine hadrosaurids (Dinosauria:

843 Ornithischia). Zoological Journal of the Linnean Society 159:398-434.

844 Evans DC, Bavington R, Campione NE. 2009. An unusual hadrosaurid braincase from the

845 Dinosaur Park Formation and the biostratigraphy of Parasaurolophus (Ornithischia:

846 Lambeosaurinae) from southern Alberta. Canadian Journal of Earth Sciences 46:791-

847800.

848 Evans DC, Forster CA, Reisz RR. 2005. The type specimen of Tetragonosaurus erectofrons

849 (Ornithischia: Hadrosauridae) and the identification of juvenile lambeosaurines. Dinosaur

$850 \quad$ Provincial Park, a spectacular ancient ecosystem revealed:349-366.

851 Evans DC, Reisz RR. 2007. Anatomy and relationships of Lambeosaurus magnicristatus, a

852 crested hadrosaurid dinosaur (Ornithischia) from the Dinosaur Park Formation, Alberta.

$853 \quad$ Journal of Vertebrate Paleontology 27:373-393.

854 Evans DC, Reisz RR, Dupuis K. 2007. A juvenile Parasaurolophus (Ornithischia:

855 Hadrosauridae) braincase from Dinosaur Provincial Park, Alberta, with comments on

856 crest ontogeny in the genus. Journal of Vertebrate Paleontology 27:642-650. 
857 Fassett JE. 2000. Geology and coal resources of the Upper Cretaceous Fruitland Formation,

858 San Juan Basin, New Mexico and Colorado: U.S. Geological Society Professional

$859 \quad$ Paper, v. 1625-B, p. Q1-Q131.

860 Fassett JE. 2010. Stratigraphic nomenclature of rock strata adjacent to the Cretaceous-Tertiary

861 interface in the San Juan Basin, in Fassett, JE, Zeigler, KE, and Lueth, VW, eds.,

862 Geology of the Four Corners Country: New Mexico Geological Society 61st Annual Fall

863 Field Conference Guidebook, p. 113-124.

864 Fassett JE, Heizler MT. 2017. An improved new age for the C33N-C32R paleomagnetic

865 reversal, San Juan Basin, NW New Mexico and SW Colorado. New Mexico Geological

866 Society Guidebook, 68 ${ }^{\text {th }}$ Field Conference, Geology of the Ouray-Silverton Area, p. 115-

$867 \quad 121$.

868 Fassett JE, Hinds JS. 1971. Geology and fuel resources of the Fruitland Formation and Kirtland

869 Shale of the San Juan Basin, New Mexico and Colorado: U.S. Geological Survey

$870 \quad$ Professional Paper, v. 676, p. 1-76.

871 Fassett JE, Steiner MB. 1997. Precise age of C33N-C32R magnetic polarity reversal, San Juan

872 Basin, New Mexico and Colorado: New Mexico Geological Society, Guidebook, v. 48, p.

$873 \quad 239-247$.

874 Farke AA, Chok DJ, Herrero A, Scolieri B, Werning S. 2013. Ontogeny in the tube-crested

875 dinosaur Parasaurolophus (Hadrosauridae) and heterochrony in hadrosaurids. PeerJ

$876 \quad 1: \mathrm{e} 182$.

877 Fowler DW. 2017. Revised geochronology, correlation, and dinosaur stratigraphic ranges of the

878 Santonian-Maastrichtian (Late Cretaceous) formations of the Western Interior of North

$879 \quad$ America. PloS one 12:e0188426.

880 Fowler DW, Fowler EA. 2020. Transitional evolutionary forms in chasmosaurine ceratopsid

881 dinosaurs: evidence from the Campanian of New Mexico. PeerJ 8:e9251.

882 Gates TA, Horner JR, Hanna RR, Nelson CR. 2011. New unadorned hadrosaurine hadrosaurid 
(Dinosauria, Ornithopoda) from the Campanian of North America. Journal of Vertebrate Paleontology 31:798-811.

885 Gates TA, Jinnah Z, Levitt C, Getty MA. 2014. New hadrosaurid specimens from the lowermiddle Campanian Wahweap Formation of Utah. Hadrosaurs. Indiana University Press, Bloomington, Indiana, USA:156-173.

Gates TA, Lund EK, Boyd CA, Deblieux DD, Titus AL, Evans DC, Getty MA, Kirkland JI, Eaton JG. 2013. Ornithopod dinosaurs from the Grand Staircase-Escalante National

Gates TA, Prieto-Márquez A, Zanno LE. 2012. Mountain building triggered Late Cretaceous North American megaherbivore dinosaur radiation. PloS one 7:e42135.

Gates TA, Sampson SD. 2007. A new species of Gryposaurus (Dinosauria: Hadrosauridae) from the Late Campanian Kaiparowits Formation. Zoological Journal of the Linnean Society 151:351-376.

Gates TA, Sampson SD, Delgado-Jesus CR, Zanno LE, Eberth DA, Hernandez-Rivera R, Martinez MCA, Kirkland JI. 2007. Velafrons coahuilensis, a new lambeosaurine hadrosaurid (Dinosauria: Ornithopoda) from the late Campanian Cerro del Pueblo Formation, Coahuila, Mexico. Journal of Vertebrate Paleontology 27:917-930.

Godefroit P, Alifanov V, Bolotsky YL. 2004. A re-appraisal of Aralosaurus tubiferus (Dinosauria, 903 Hadrosauridae) from the Late Cretaceous of Kazakhstan. Bulletin de L'Institut Royal des

Godefroit P, Bolotsky YL, Bolotsky IY. 2012. Osteology and relationships of Olorotitan arharensis, a hollow-crested hadrosaurid dinosaur from the latest Cretaceous of Far Eastern Russia. Acta Palaeontologica Polonica 57:527-560. DOI: 
909 Godefroit P, Bolotsky YL, Itterbeeck JV. 2004. The lambeosaurine dinosaur Amurosaurus

910 riabinini, from the Maastrichtian of Far Eastern Russia. Acta Palaeontologica Polonica

$911 \quad 49: 585-618$.

912 Godefroit P, Bolotsky YL, Lauters P. 2012. A new saurolophine dinosaur from the latest

$913 \quad$ Cretaceous of far Eastern Russia. PLoS One 7:e36849.

914 Godefroit P, Zan S, Jin L. 2001. The Maastrichtian (Late Cretaceous) lambeosaurine dinosaur

915 Charonosaurus jiayinensis from north-eastern China. Bulletin de l'Institut Royal des

916 Sciences Naturelles de Belgique. Sciences de la Terre 71:119-168.

917 Herring, SW. 1974. A biometric study of suture fusion and skull growth in peccaries. Anatomy

$918 \quad$ and Embryology, 146(2), pp.167-180.

919 Herring, SW. 2008. Mechanical influences on suture development and patency. In Craniofacial 920 sutures (Vol. 12, pp. 41-56). Karger Publishers.

921 Holroyd PA, Hutchison JH. 2016. Fauna and setting of the Adelolophus hutchisoni type locality 922 in the Upper Cretaceous (Campanian) Wahweap Formation of Utah. PaleoBios 33.

923 Hopson JA. 1975. The evolution of cranial display structure in hadrosaurian dinosaurs.

924 Paleobiology 1:21-43.

925 Horner JR, Weishampel DB, Forster C. 2004. Hadrosauridae. In: Weishampel DB, Dodson P, 926 Osmólska H eds. The Dinosauria. Berkeley: University of California Press, 438-463.

927 Hunt AP. 1991. Integrated vertebrate, invertebrate and plant taphonomy of the Fossil Forest 928 area (Fruitland and Kirtland formations: Late Cretaceous), San Juan County, New 929 Mexico, U.S.A. Palaeogeography, Palaeoclimatology, Palaeoecology 88:85-107.

930 Hunt AP, Lucas SG. 1992. Stratigraphy, paleontology and age of the Fruitland and Kirtland 931 formations (Upper Cretaceous), San Juan Basin, New Mexico: New Mexico Geological 932 Society, 43rd Field Conference, Guidebook, p. 217-239. 
933 Joyce WG, Lyson TR, Sertich JJ. 2018. A new species of trionychid turtle from the Upper

934 Cretaceous (Campanian) Fruitland Formation of New Mexico, USA. Journal of

$935 \quad$ Paleontology 92:1107-1114.

936 Lucas SG, Hunt AP, Sullivan RM. 2006. Stratigraphy and age of the Upper Cretaceous Fruitland

937 Formation, west-central San Juan Basin, New Mexico: New Mexico Museum of Natural

938 History and Science Bulletin, v. 35, p. 1-6.

939 Lull RS, Wright NE. 1942. Hadrosaurian dinosaurs of North America. Geological Society of

$940 \quad$ America Special Paper 40:1-242.

941 Lund EK, Gates TA. 2006. A historical and biogeographical examination of hadrosaurian

942 dinosaurs. In: Lucas SG, Sullivan RM eds. Late Cretaceous Vertebrates from the

943 Western Interior. New Mexico Museum of Natural History and Science Bulletin.

944 Albuquerque: New Mexico Museum of Natural History and Science, 263-276.

945 Marsh OC. 1881. Principal characters of American Jurassic dinosaurs. Part IV. American

$946 \quad$ Journal of Science, series 3 21:167-170.

947 Ostrom JH. 1961. A new species of hadrosaurian dinosaur from the Cretaceous of New Mexico.

$948 \quad$ Journal of Paleontology 35:575-577.

949 Owen R. 1842. Report on British fossil reptiles. Report of the British Association of Advanced

950 Sciences 9:60-204.

951 Parks WA. 1922. Parasaurolophus walkeri: a new genus and species of crested trachodont

952 dinosaur. Univ. Library.

953 Parks WA. 1923. Corythosaurus intermedius, a new species of trachodont dinosaur. University

954 of Toronto Studies, Geological Series 15:5-57.

955 Prieto-Márquez A. 2005. New information on the cranium of Brachylophosaurus canadensis

956 (Dinosauria, Hadrosauridae), with a revision of its phylogenetic position. Journal of

957 Vertebrate Paleontology 25:144-156.

958 Prieto-Márquez A. 2010. Global phylogeny of Hadrosauridae (Dinosauria: Ornithopoda) using 

502.

961 Prieto-Márquez A, Fondevilla V, Sellés AG, Wagner JR, Galobart À. 2018. Adynomosaurus

962 arcanus, a new lambeosaurine dinosaur from the Late Cretaceous Ibero-Armorican

963 Island of the European Archipelago. Cretaceous Research.

964 Prieto-Márquez A, Wagner JR, Bell PR, Chiappe LM. 2014. The late-surviving 'duck-billed'

965 dinosaur Augustynolophus from the upper Maastrichtian of western North America and 966 crest evolution in Saurolophini. Geological Magazine 152:225-241.

967 Ryan M, Evans DC. 2005. Ornithischian dinosaurs. In: Currie PJ, Koppelhus EB eds. Dinosaur

968 Provincial Park: A spectacular ancient ecosystem revealed. Bloomington: Indiana $969 \quad$ University Press, 312-348.

970 Sampson SD, Loewen MA. 2010. Unraveling a radiation: a review of the diversity, stratigraphic

971

972

973

974 distribution, biogeography, and evolution of horned dinosaurs (Ornithischia: Ceratopsidae). In: Ryan MJ, Chinnery-Allgier BJ, Eberth, DA New Perspectives on Horned Dinosaurs: The Royal Tyrrell Museum Ceratopsian Symposium. Bloomington: Indiana University Press 405-427.

Sereno PC. 1986. Phylogeny of the bird-hipped dinosaurs (Order Ornithischia). National Geographic Research 2:234-256.

Strobell Jr JD, O'Sullivan RB, Mytton JW, Erpenbeck MF. 1985. Preliminary geologic map of the 980 Pretty Rock Quadrangle. 1:24,000. U.S. Geological Survey, Miscellaneous Field Studies Map MF-1788. U.S. Geological Survey, Reston, Virginia.

Seeley HG. 1888. On Thecospondylus daviesi (Seeley), with some remarks on the classification of the Dinosauria. Quarterly Journal of the Geological Society of London 44:79-86. 
984

985

986

987

988

989

990

991

992

993

994

995

996

997

998

999

1000

1001

1002

1003

1004

1005

1006

1007

(Upper Campanian), San Juan Basin, New Mexico. Journal of Vertebrate Paleontology 19:126-39.

Sullivan, R.M., and Lucas, S.G., 2003, The Kirtlandian, a new land-vertebrate "age" for the Late Cretaceous of western North America, in Lucas, S.G., Semken, S.C., Berglof, W.R., and Ulmer-Scholle, D.S., eds., Geology of the Zuni Plateau: New Mexico Geological Society 54th Field Conference Guidebook, p. 375-383.

Sullivan, R.M., and Lucas, S.G., 2006, The Kirtlandian land-vertebrate "age"-faunal composition, temporal position and biostratigraphic correlation in the nonmarine Upper Cretaceous of western North America: New Mexico Museum of Natural History and Science Bulletin $35: 7-29$.

Sullivan RM, and Lucas SG. 2014. Stratigraphic distribution of hadrosaurids in the Upper Cretaceous Fruitland, Kirtland, and Ojo Alamo formations, San Juan Basin, New Mexico. Pp. 361-384, In: DA Eberth and DC Evans (eds) Hadrosaurs, Indiana University Press, Indianapolis.

Sullivan RM, Williamson TE. 1999. A new skull of Parasaurolophus (Dinosauria: Hadrosauridae) from the Kirtland Formation of New Mexico and a revision of the genus. New Mexico Museum of Natural History and Science Bulletin, Albuquerque.

Weishampel DB. 1997. Dinosaurian cacophany: Inferring function in extinct organisms.

$$
\text { BioScience 47:150-159. }
$$

Weishampel DB, Jenson JA. 1979. Parasaurolophus (Reptilia: Hadrosauridae) from Utah. Journal of Paleontology 53:1422-1427.

Weishampel DB, Norman DB, Grigorescu D. 1993. Telmatosaurus transsylvanicus from the Late Cretaceous of Romania: the most basal hadrosaurid dinosaur. Palaeontology 36:361-385. 
1008 Wiersma JP, Irmis RB. 2018. A new southern Laramidian ankylosaurid, Akainacephalus

1009 johnsoni gen. et sp. nov., from the upper Campanian Kaiparowits Formation of southern

$1010 \quad$ Utah, USA. PeerJ 6:e5016.

1011 Wilfarth, M. 1939. Die nasenbasis der Lambeosaurinae. Sonder-Abdruck aus dem

1012 Zentralblatt f. Min. etc. Abt. B. 1:24-39.

1013 Williamson, T.E., 2000. Review of Hadrosauridae (Dinosauria, Ornithischia) from the San Juan

1014 Basin, New Mexico. Dinosaurs of New Mexico. SG Lucas and AB Heckert (eds.). New

1015 Mexico Museum of Natural History and Science, Bulletin, 17, pp.191-213.

1016 Wiman C. 1931. Parasaurolophus tubicen n. sp. aus der Kreide in New Mexico.

1017 Wolberg DL, Hall JP, Bellis D, Chavez WX, Anderson 0, Moro R, Gil A. 1988. Regional

1018 historic. stratigraphic, and paleontologic framework of the Late Cretaceous

1019 (Campanian--Maastrichtian) Fossil Forest locality near Split Lips Flats, San Juan Basin,

$1020 \quad$ New Mexico. New Mexico Bureau of Mines and Mineral Resources, Bulletin 122:7-21.

1021 Xing H, Wang D, Han F, Sullivan C, Ma Q, He Y, Hone DW, Yan R, Du F, Xu X. 2014a. A new

1022 basal hadrosauroid dinosaur (Dinosauria: Ornithopoda) with transitional features from

1023 the Late Cretaceous of Henan Province, China. PLoS One 9:e98821.

1024 Xing H, Zhao X, Wang K, Li D, Chen S, Mallon JC, Zhang Y, Xu X. 2014b. Comparative

1025 Osteology and Phylogenetic Relationship of Edmontosaurus and Shantungosaurus

1026 (Dinosauria: Hadrosauridae) from the Upper Cretaceous of North America and East

1027 Asia. Acta Geologica Sinica (English Edition) 88:1623-1652. 


\section{Figure 1}

Holotype skulls of the three currently diagnosed species within the Parasaurolophus clade.

A) Parasaurolophus cyrtocristatus (FMNH P-27393); B) Parasaurolophus walkeri (ROM 768); and C) Parasaurolophus tubicen (NMMNH P-25100). Ages associated with each skull represent the approximate timing of each taxon. 


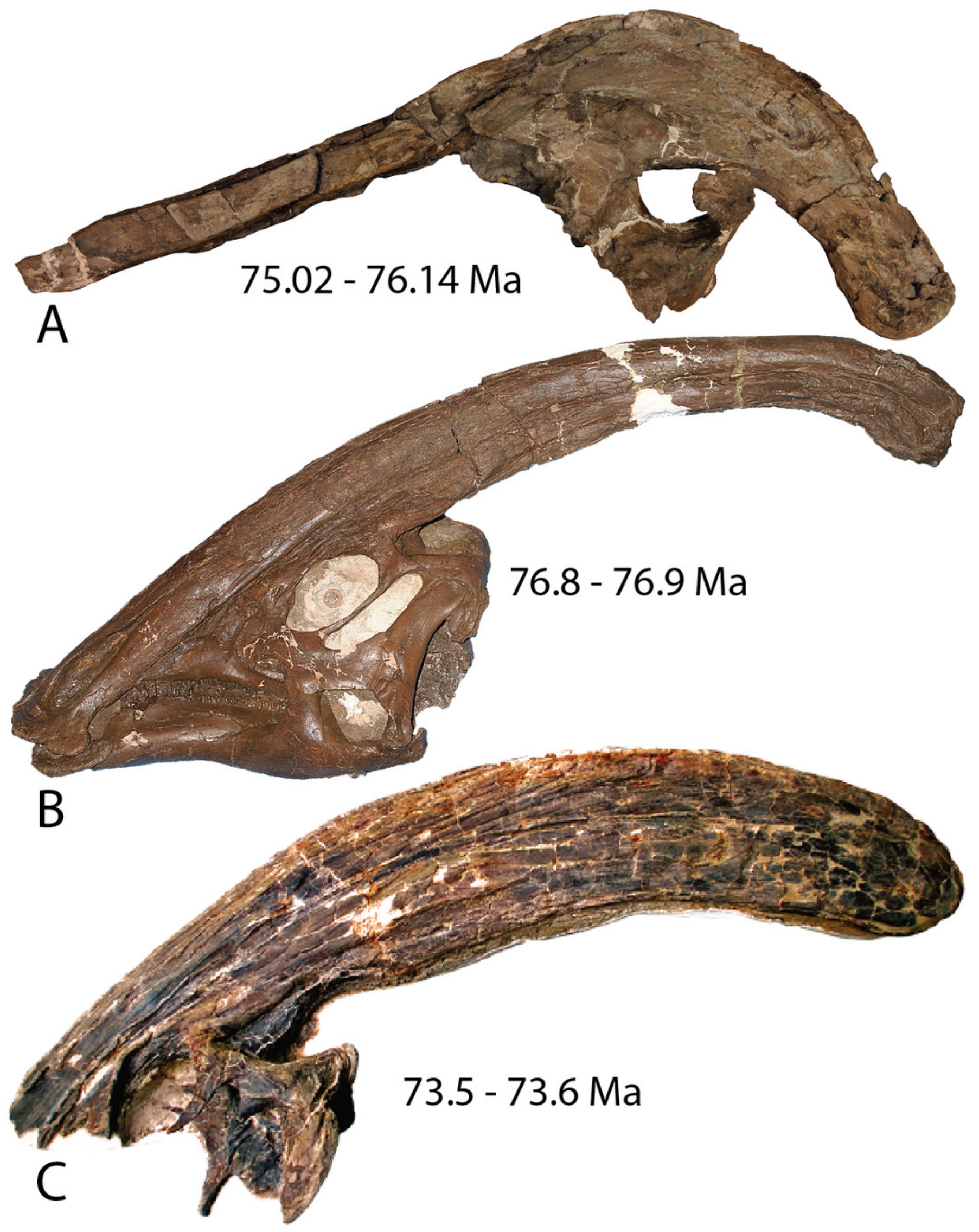


Figure 2

Map of the southern San Juan Basin

A) exposures of the Upper Cretaceous Fruitland and Kirtland formations across northwestern New Mexico and B) approximate locations of the holotype (FMNH P-27393) and referred (DMNH EPV.132300) specimens of Parasaurolophus cyrtocristatus in the Fossil Forest Member of the Fruitland Formation. Map credit: "A new species of trionychid turtle from the Upper Cretaceous (Campanian) Fruitland Formation of New Mexico, USA" COPYRIGHT: () 2018, The Paleontological Society 'Reprinted with permission'. 

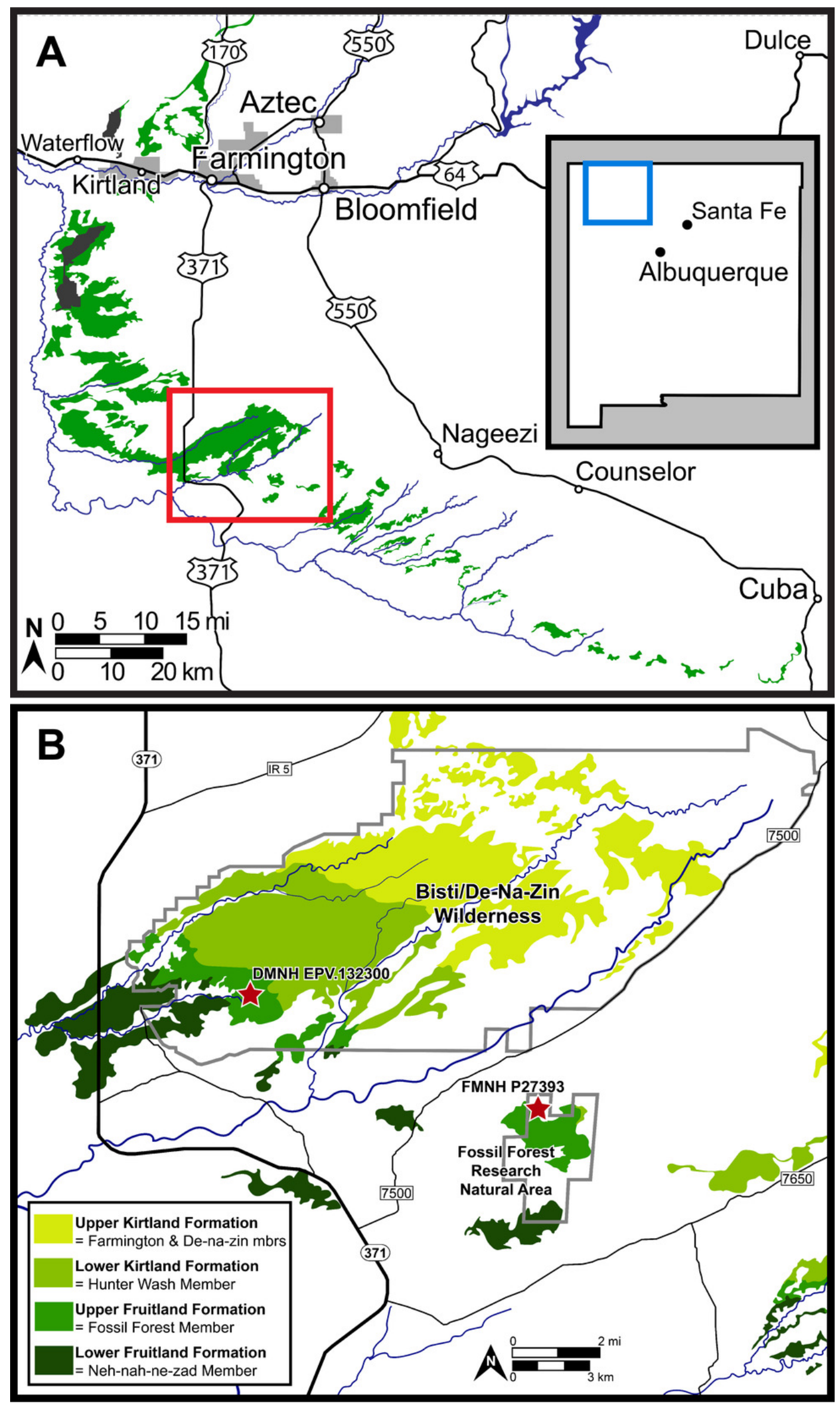
Figure 3

Skull of Parasaurolophus cyrtocristatus (FMNH P-27393).

A) left lateral view and B) right lateral view. Scale bar equals $10 \mathrm{~cm}$.

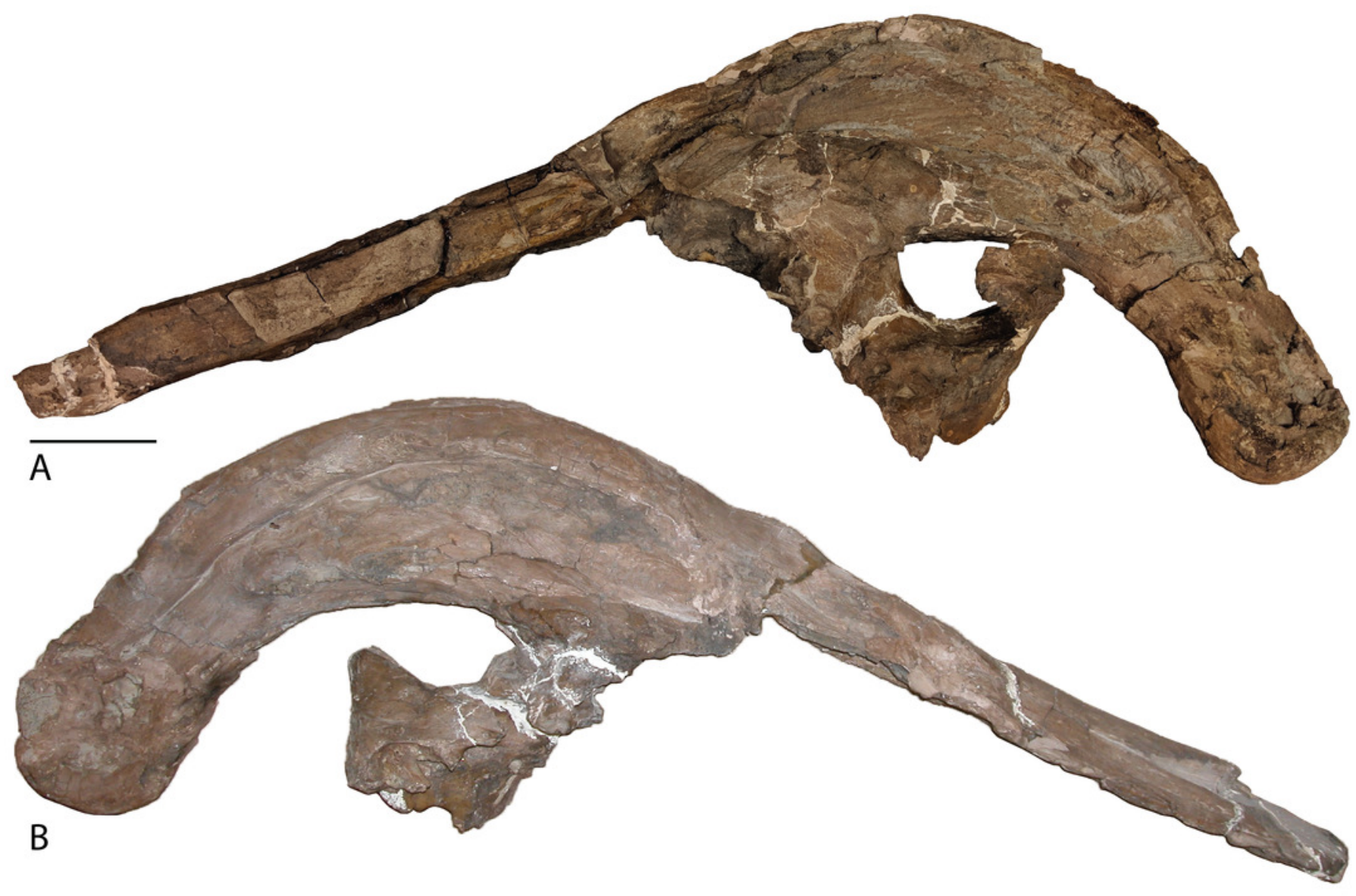




\section{Figure 4}

Skull of Parasaurolophus cyrtocristatus (DMNH EPV.132300)

A) Photograph of right lateral side; B) Illustration of right lateral side; C) Photograph of left lateral side; and D) Illustration of left lateral side. Abbreviations: Bso, Basioccipital; Bsp, Basisphenoid; Exo, Exoccipital; F, Frontal; La, Lacrimal; Lsp, Laterosphenoid; Na, Nasal; Osp, Orbitosphenoid; Pa, Parietal; Pmd, premaxilla dorsal process; Pml, premaxilla lateral process; Po, Postorbital; Pr, Prootic; Prf, Prefrontal; Ps, Presphenoid; Sq, Squamosal. 


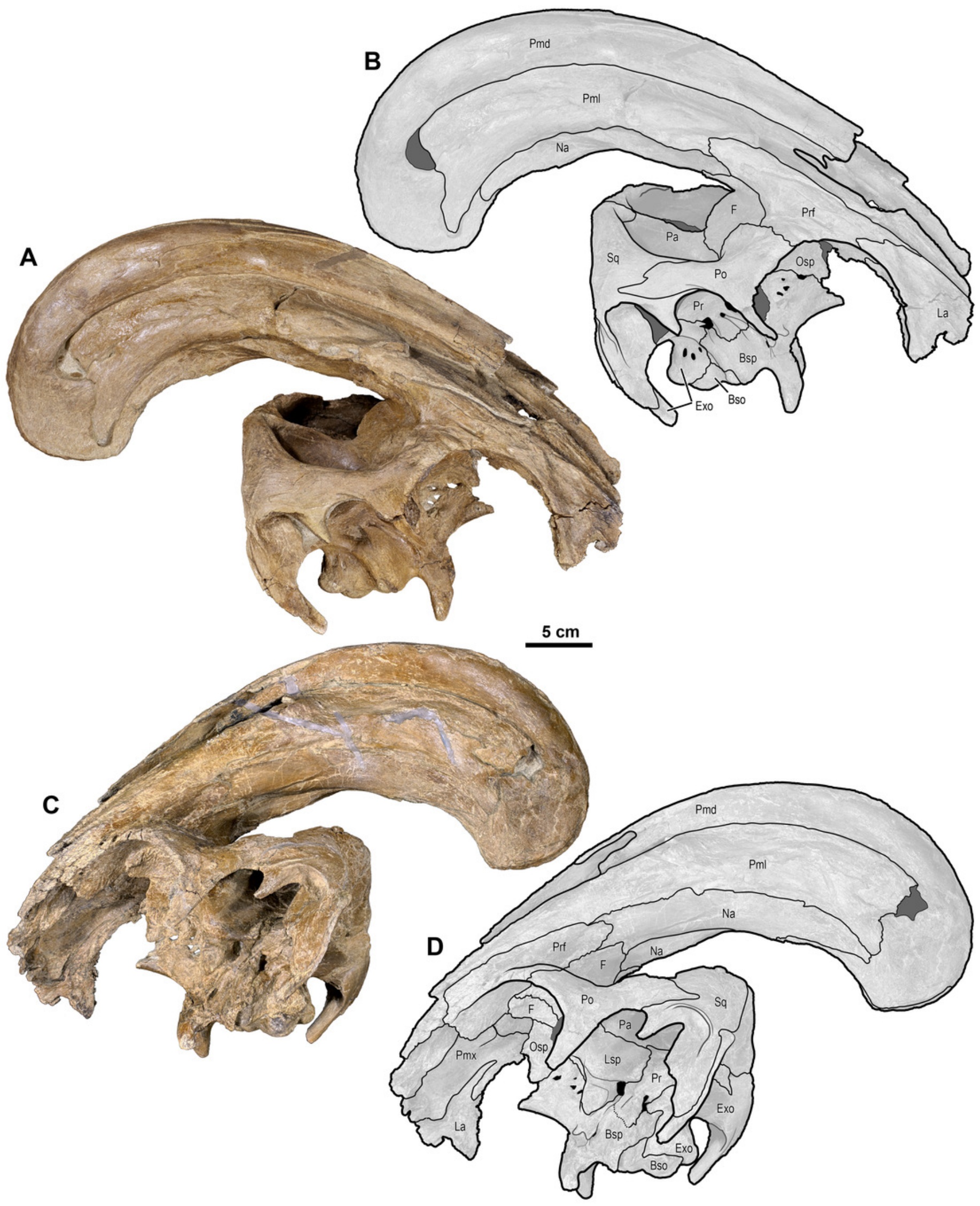




\section{Figure 5}

Skull of Parasaurolophus cyrtocristatus (DMNH EPV.132300)

A) Photograph of ventral skull; B) Illustration of ventral skull; C) Photograph of posterior skull;

D) Illustration of posterior skull. Abbreviations: Bso, Basioccipital; Bsp, Basisphenoid; Exo, Exoccipital; F, Frontal; Fm, Foramen Magnum; La, Lacrimal; Lsp, Laterosphenoid; Na, Nasal;

Pa, Parietal; Pmd, premaxilla dorsal process; Pml, premaxilla lateral process; Pmx, Premaxilla; Po, Postorbital; Pr, Prootic; Prf, Prefrontal; Ps, Presphenoid; So, Supraoccipital; Sq, Squamosal. 

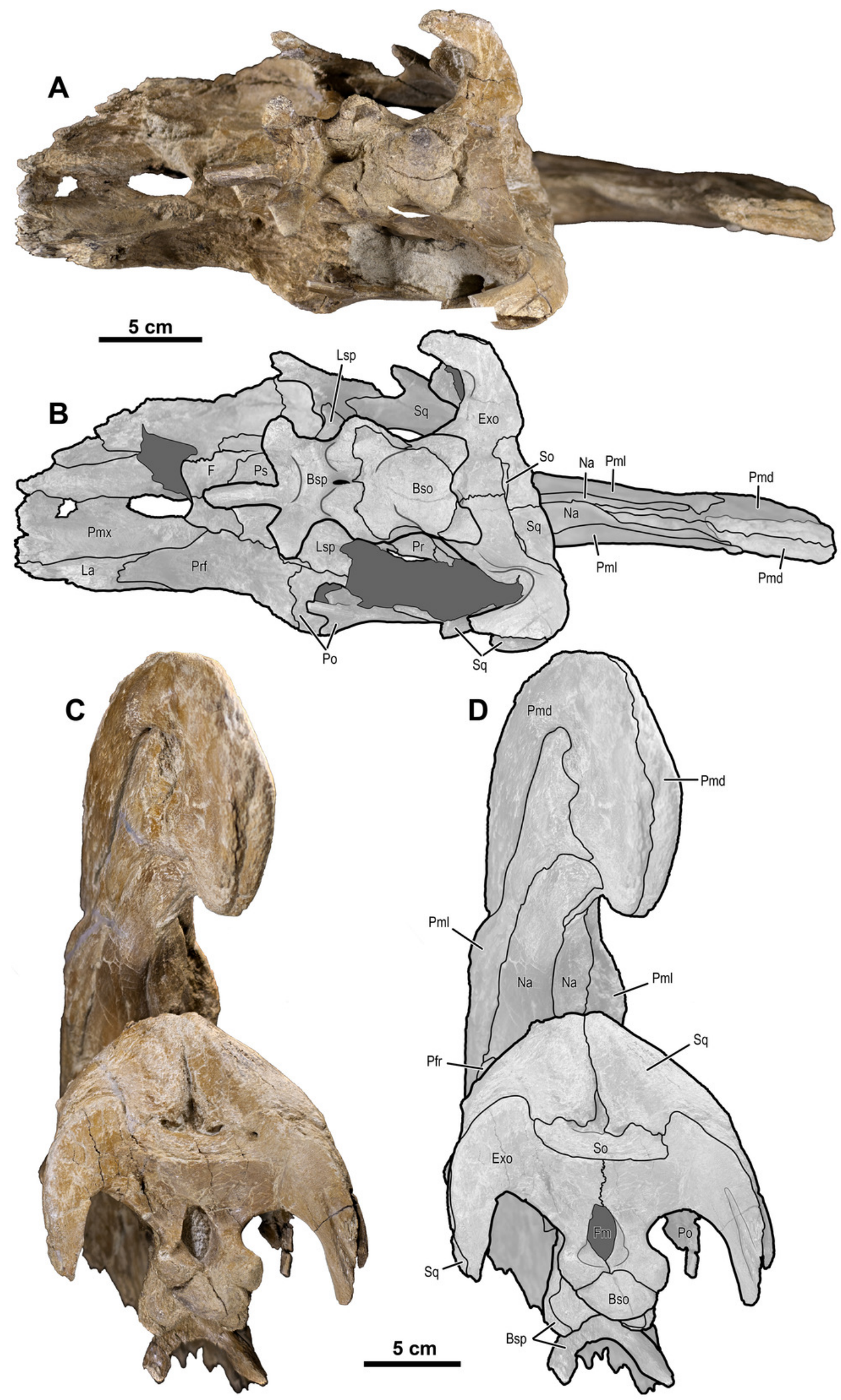

Peer] reviewing PDF | (2020:01:44845:2:1:NEW 3 Dec 2020) 


\section{Figure 6}

Detailed photographs of the Parasaurolophus cyrtocristatus crest.

A) FMNH P-27393 in right lateral view; B) Cross section of the posterior cranial crest on FMNH P-27393; C) Posterior crest of FMNH P-27393 in right lateral view; D) Supracranial portion of crest on DMNH EPV.132300 with lines demarcating skull elements; E) Supracranial portion of crest on DMNH EPV.132300 without lines demarcating skull elements. Note that letters $\mathrm{z}$ and Z' denote the homologous points on the FMNH P-27393 crest. Abbreviations: Na, Nasal; Pmd, Premaxilla dorsal process; Pml, Premaxilla lateral process; pnf, premaxilla-nasal fontanelle. Scale bars equal $5 \mathrm{~cm}$. 


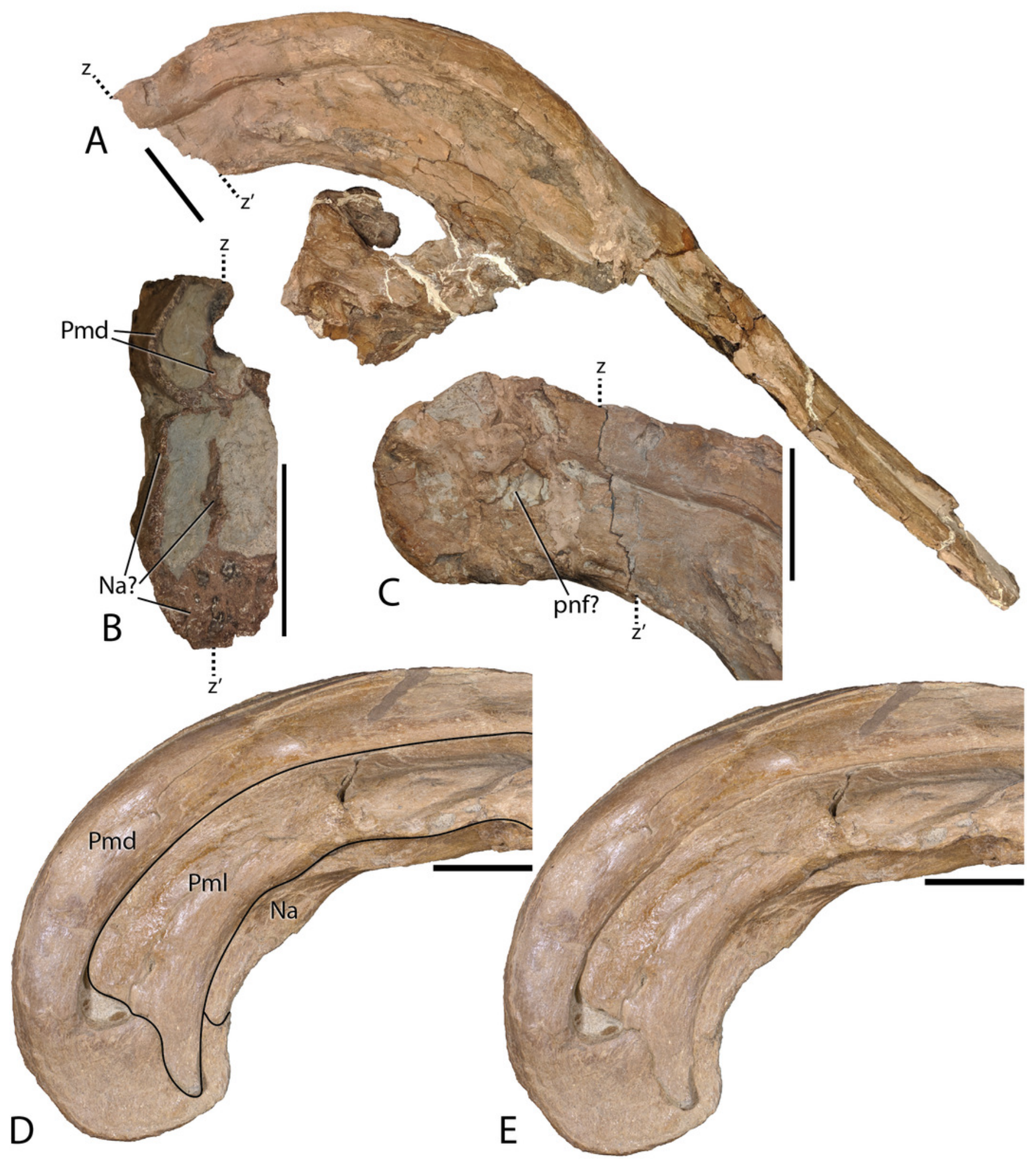


Figure 7

Anterolateral view of Parasaurolophus cyrtocristatus DMNH EPV.132300 showing the relationship of the nasal, lacrimal, and prefrontal.

Abbreviations: La, lacrimal; Na, Nasal; Pf, Prefrontal; Pm, Premaxilla. 


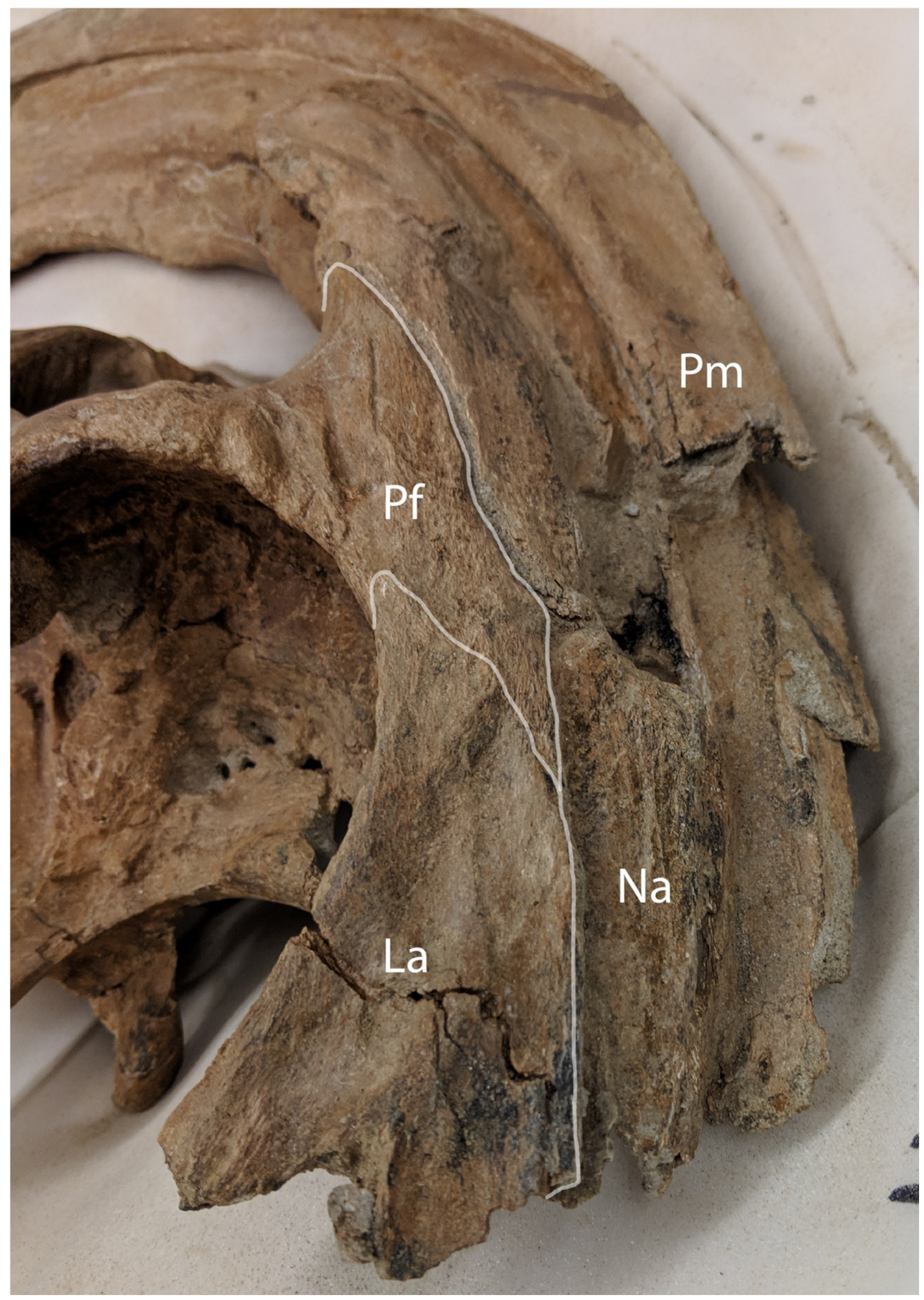




\section{Figure 8}

Parasaurolophus cyrtocristatus DMNH EPV.132300 squamosal.

A) right laterodorsal, B) and posterior view with a close-up of the quadrate cotylus notch in C) FMNH P-27393 and D) DMNH EPV.132300. Abbreviations: bptp, basipterygoid processes; Bso, Basioccipital; bst, basitubera; elsq, elevated posterior squamosal; Exo, Exoccipital; Fr, Frontal; itf, infratemporal fenestra; mr, median ramus of squamosal; Pa, Parietal; Po, Postorbital; pop, paroccipital process; prcp, precotyloid process; postcp, postcotyloid process; qc, quadrate cotylus; Spo, Supraoccipital; Sq, squamosal. Scale bar equals $5 \mathrm{~cm}$.

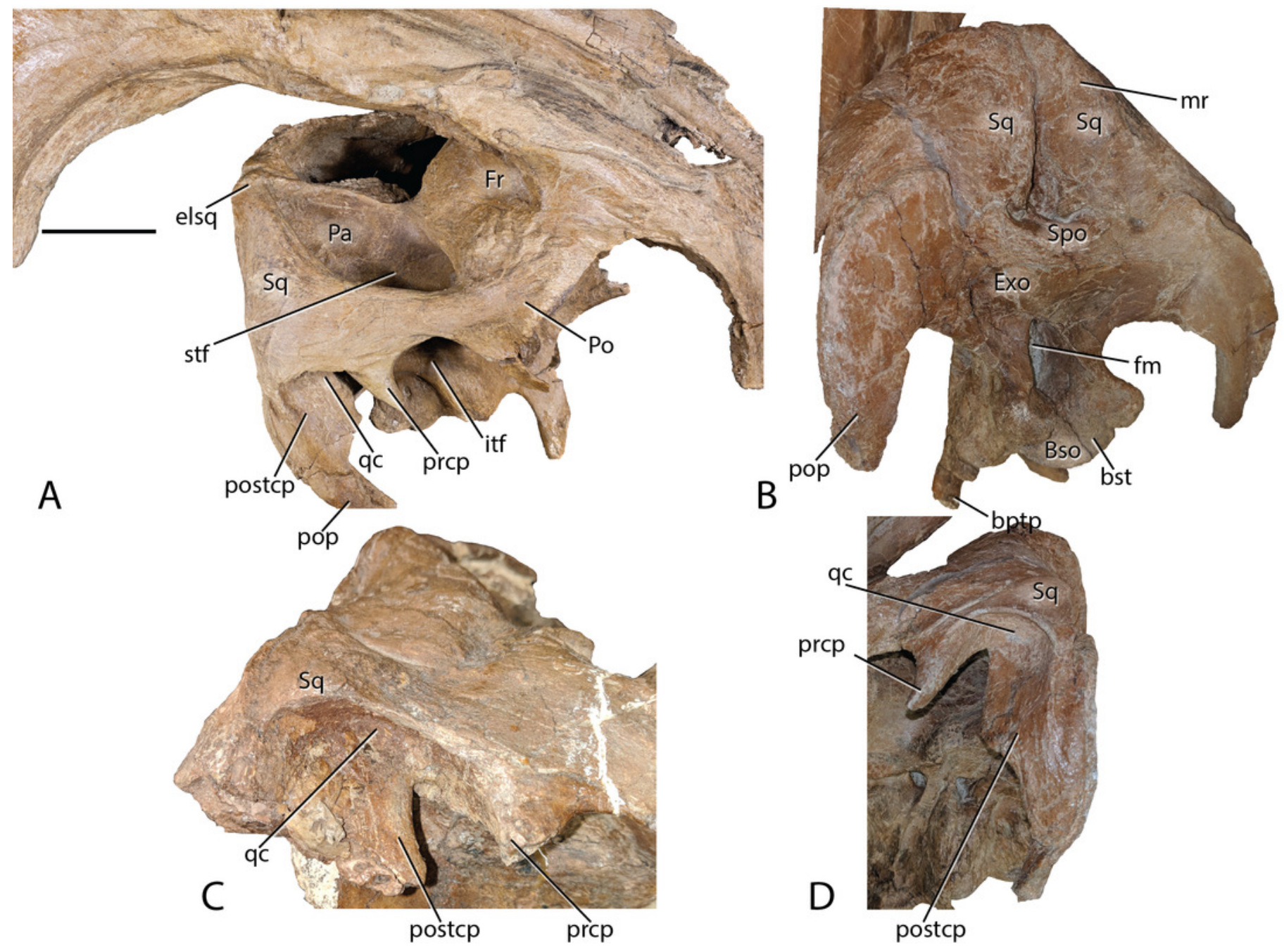




\section{Figure 9}

Parasaurolophus cyrtocristatus DMNH EPV.132300 braincase.

A) Right lateral view. B) Ventral view. Abbreviations: ap, alar process; Bso, Basioccipital;

bptp, basipterygoid processes; Bsp, Basisphenoid; bspg, basisphenoid groove; bst, basitubera; cno, cranial nerve opening; Exo, Exoccipital; ibsl, interbasisphenoid lamina; Osp, Orbitosphenoid; pop, paroccipital process; qc, quadrate cotylus; vd, Vidian Canal. Scale bars equal $5 \mathrm{~cm}$. 

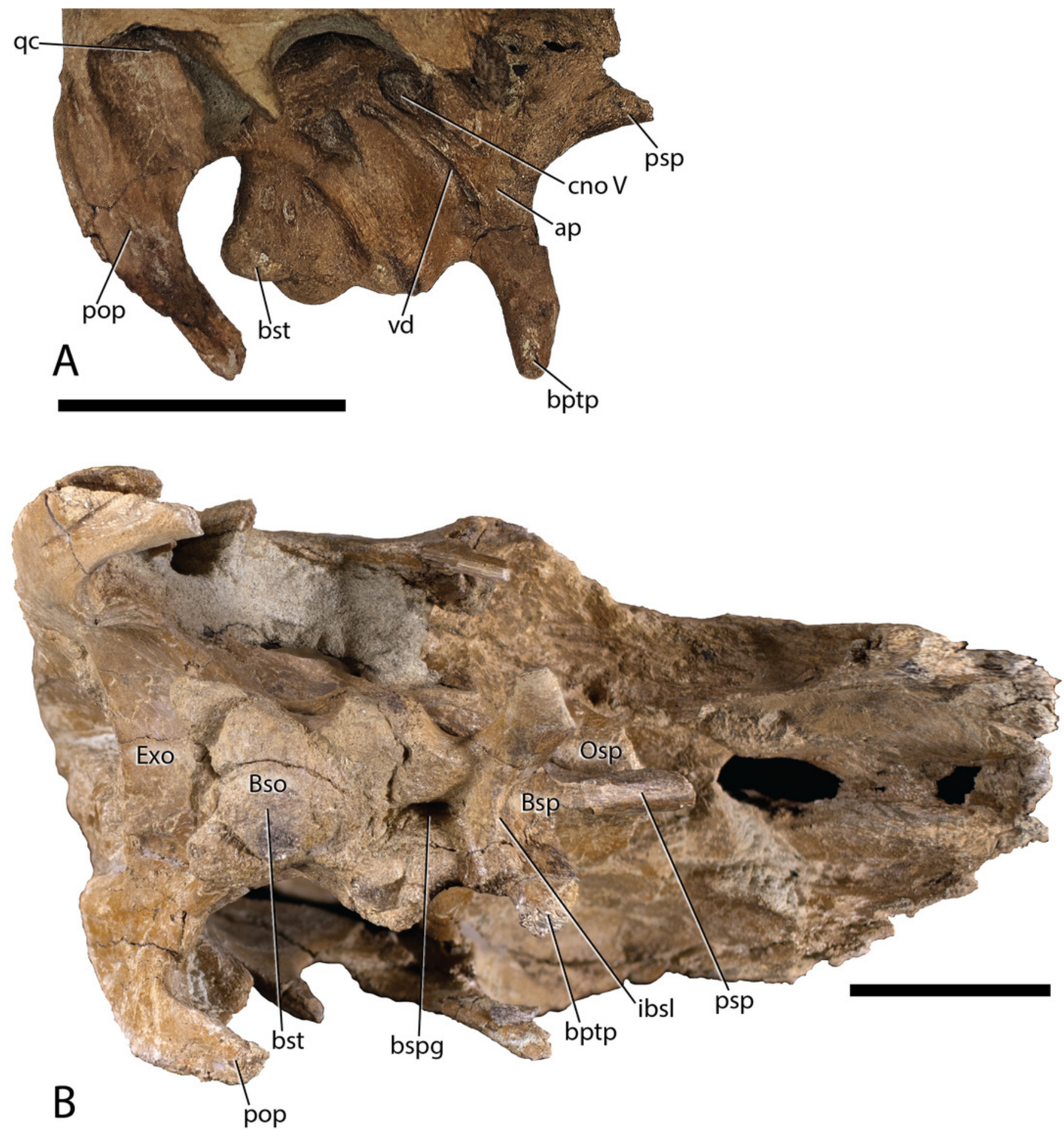


\section{Figure 10}

Mandibular elements of Parasaurolophus cyrtocristatus DMNH EPV.132300.

A) Right dentary in lateral view; B) right dentary in medial view; C) right surangular in dorsal view; right surangular in ventral view. Scale bar equals $5 \mathrm{~cm}$.
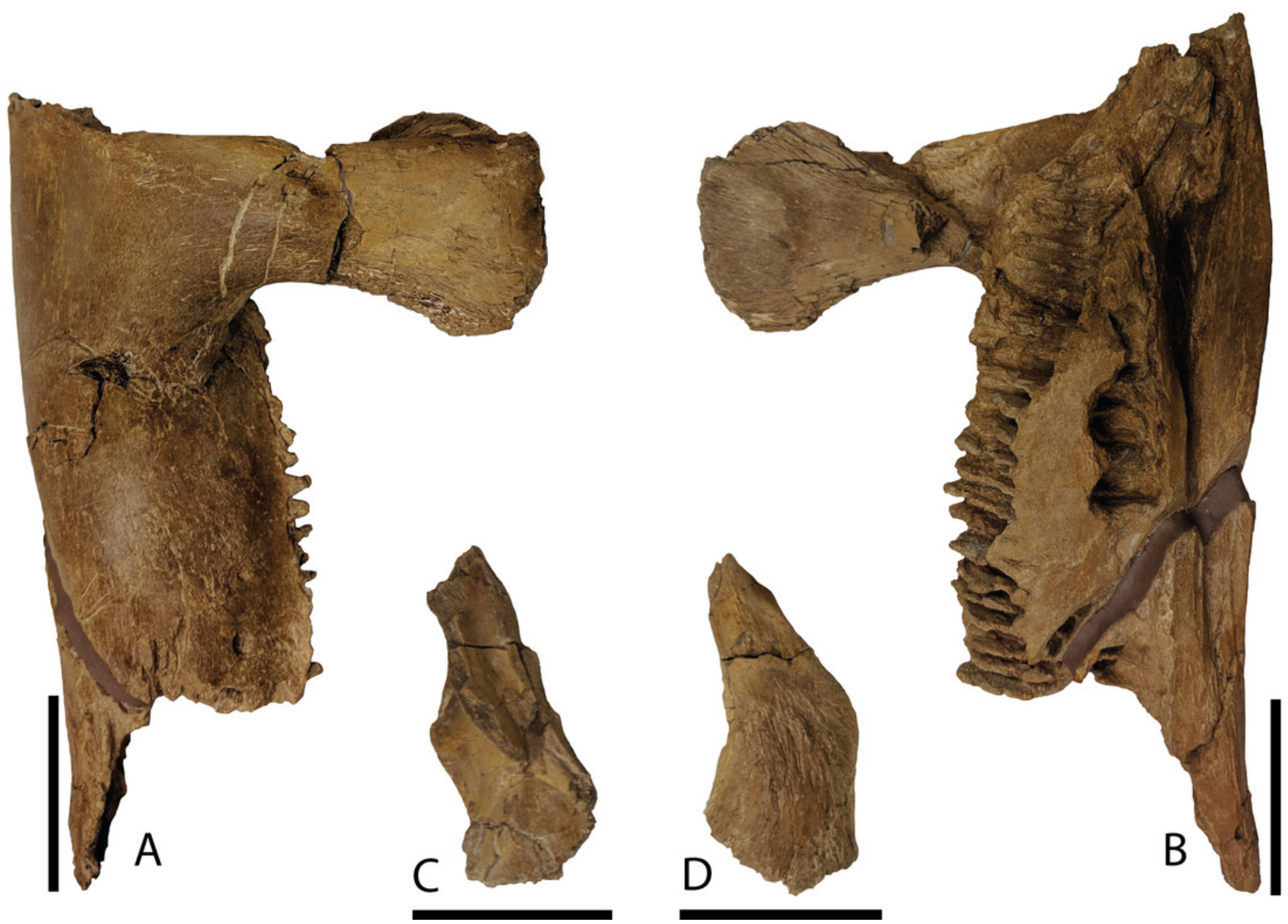


\section{Figure 11}

Strict consensus phylogenetic tree derived from 72 most parsimonious trees derived from analysis in this study.

Tree scores: tree length $1044, \mathrm{Cl} 0.399, \mathrm{RI} 0.777, \mathrm{RC} 0.310$. Underlined numbers at each node are the bootstrap values, whereas standalone numbers designate the Bremer Decay Index for that branch. Note that the Bremer indices of 4 and greater are approximations because the analysis was stopped after retaining 4.2 million trees. Grey box encloses the Parasaurolophini clade. Characters were ordered as in Prieto-Márquez et al. (2018). 


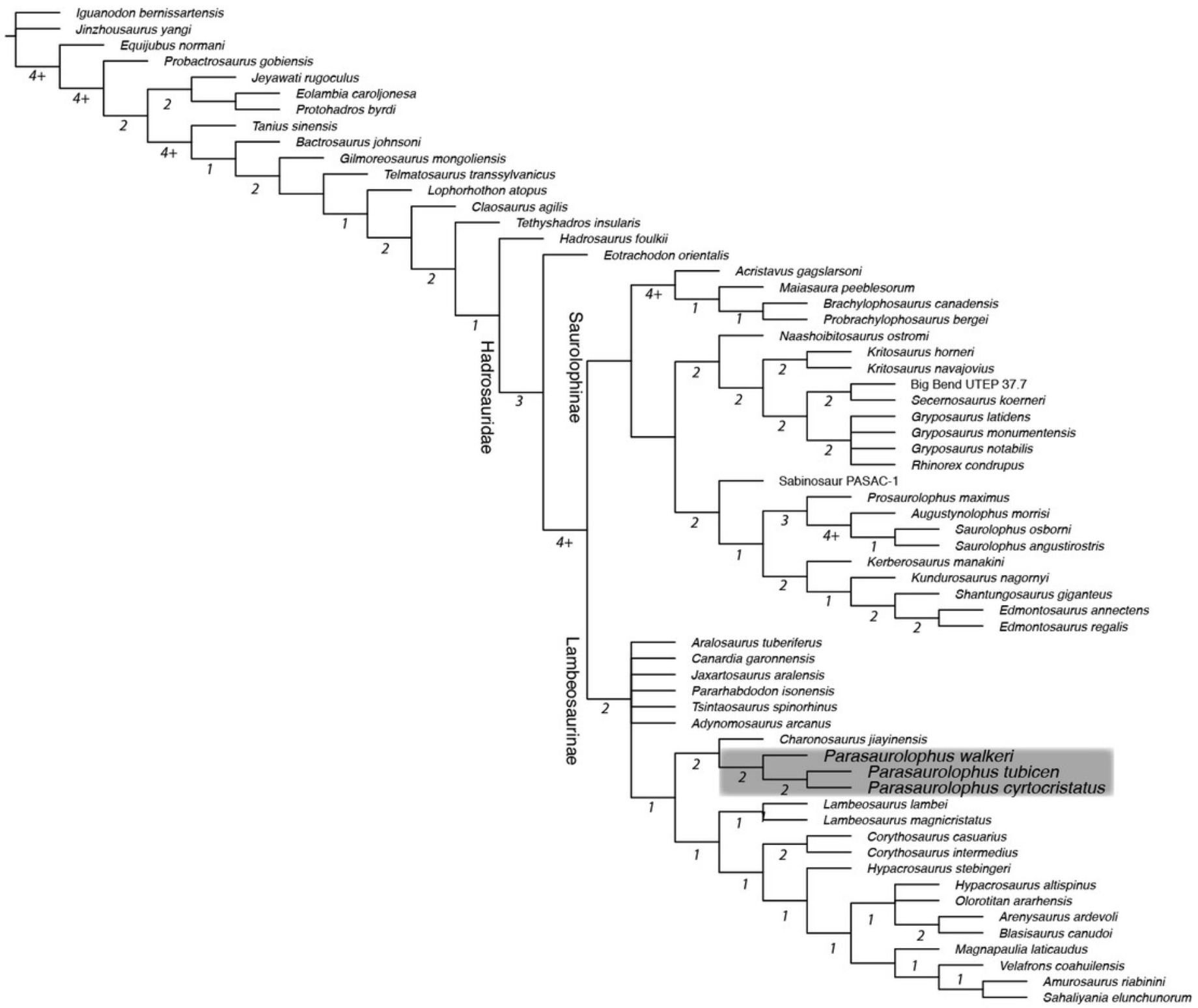




\section{Figure 12}

Photographs and illustrations of Parasaurolophus cf. cyrtocristatus UCMP 143270

A) Photograph of left lateral side; B) Illustration of left lateral side; C) Photograph of right lateral side; and D) Illustration of right lateral side. Abbreviations: Bso, Basioccipital; Bsp, Basisphenoid; Exo, Exoccipital; F, Frontal; La, Lacrimal; Lsp, Laterosphenoid; Na, Nasal; Osp, Orbitosphenoid; Pa, Parietal; Pmd, premaxilla dorsal process; Pml, premaxilla lateral process; Po, Postorbital; Pr, Prootic; Prf, Prefrontal; Ps, Presphenoid; Sq, Squamosal. 

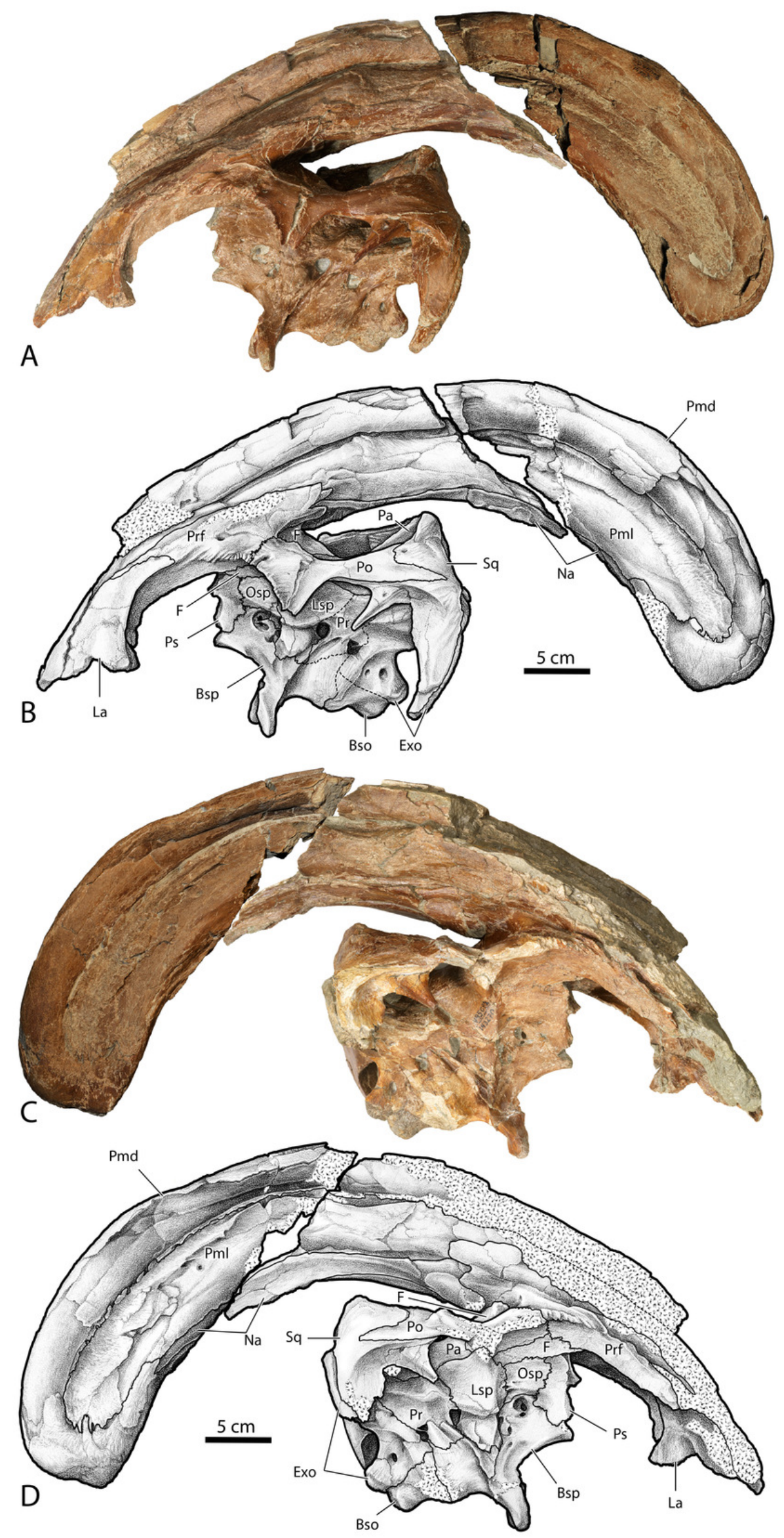

Peer) reviewing PDF | (2020:01:44845:2:1:NEW 3 Dec 2020) 


\section{Figure 13}

Photographs and illustrations of Parasaurolophus cf. cyrtocristatus UCMP 143270
A) Photograph of ventral skull; B) Illustration of ventral skull; C) Photograph of posterior skull;
D) Illustration of posterior skull. Abbreviations: Bso, Basioccipital; Bsp, Basisphenoid; Exo,
Exoccipital; FM, Foramen Magnum; La, Lacrimal; Lsp, Laterosphenoid; Na, Nasal; Osp,
Orbitosphenoid; Pmd, premaxilla dorsal process; Pml, premaxilla lateral process; Pmx,
Premaxilla; Po, Postorbital; Pr, Prootic; Prf, Prefrontal; Ps, Presphenoid; So, Supraoccipital; Sq,
Squamosal. 

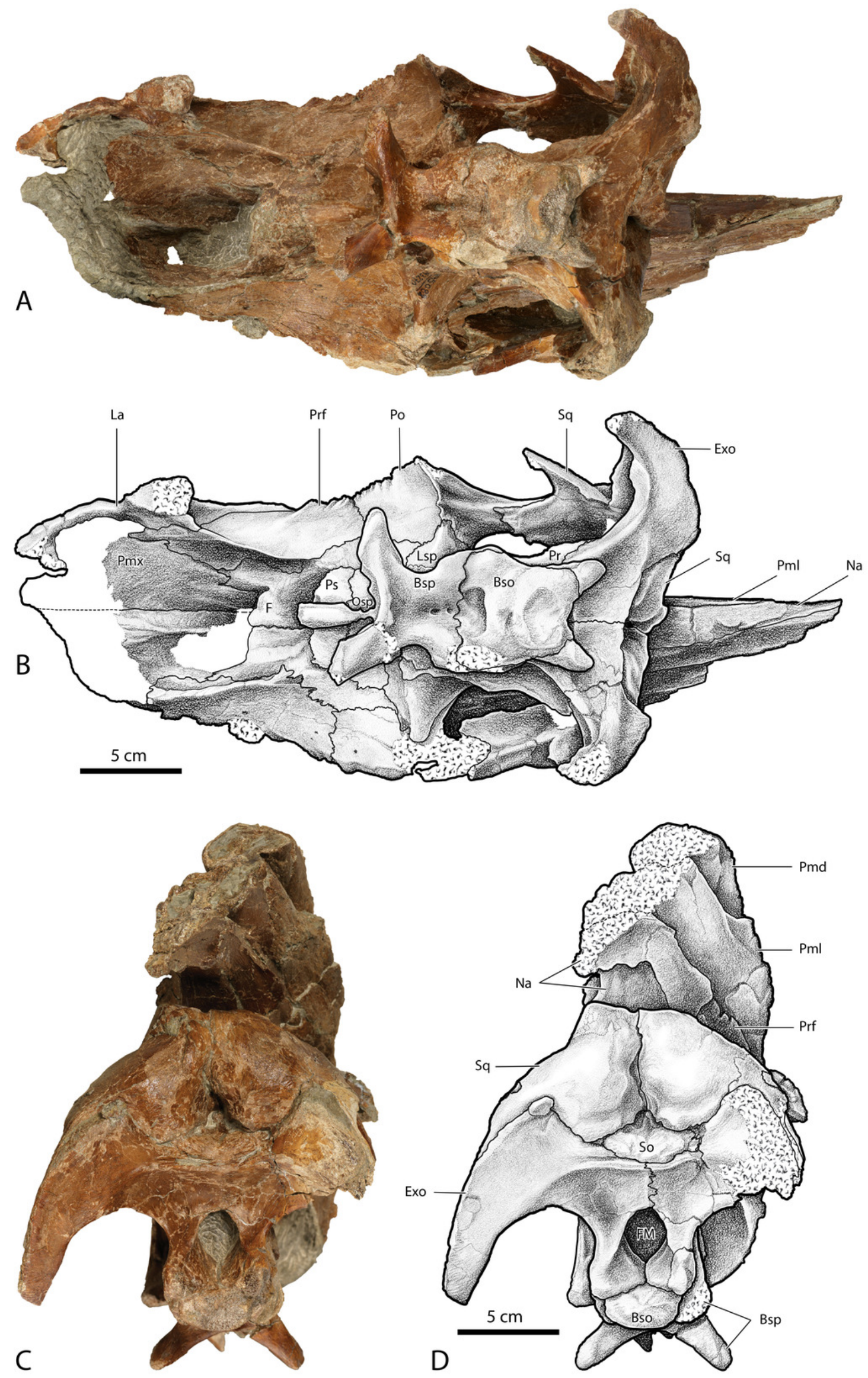

Peer) reviewing PDF | (2020:01:44845:2:1:NEW 3 Dec 2020) 